\title{
Der jüdische Adel Preußens
}

\section{The Prussian Jewish Nobility}

\author{
Jan Županič / jan.zupanic@ff.cuni.cz
}

Seminář novověkých dějin, Filozofická fakulta, Univerzita Karlova, Praha, CZ

\begin{abstract}
Different European states had different attitudes towards Jews and their social standing. In the Habsburg monarchy, several hundred people of the Jewish faith were ennobled between 1789 and 1918 (both in Austria and later in Hungary), while Jews were granted equal social status in 1867. In Prussia the social status of Jews had improved since the rule of Frederick II and in 1812 they were able to become Prussian citizens. However, Jewish emancipation reached a high point in July 1869 when a law on equal religious rights was declared in Prussia as well as in all the states of the North German Confederation. However, in Prussia the issue of granting aristocratic titles to people of the Jewish faith or of Jewish origin was, of course, more vexed and the ennoblement of these people was very rare.
\end{abstract}

\section{Keywords}

Prussia, nobility, ennoblement, elites, Jews 
Wenn wir mit dem Abstand eines Jahrhunderts seit dem Untergang der mitteleuropäischen Monarchien die Nobilitierungspolitik der beiden damals größten Staaten, der Habsburgermonarchie und Preußens, betrachten, erscheint interessant, wie gravierend sich Haltungen und Strategien beider Staaten voneinander unterschieden. Der Unterschied fällt dabei nicht allein quantitativ ins Auge, sondern auch durch die soziale Struktur der Neuadeligen, wobei vielleicht am meisten die völlig gegensätzliche Einstellung beider Länder zur Nobilitierung von Personen jüdischen Glaubens überrascht.

Auf der Grundlage langjähriger Forschungen darf konstatiert werden, dass in den Jahren 1789-1918 in der Österreich gegen 240 Personen (und viele andere in Ungarn) mosaischen Glaubens nobilitiert wurden, von denen viele eine weitere Erhebung (zu Rittern oder Baronen) erfuhren. ${ }^{1}$ Die liberale Haltung Österreichs weist jedoch einen markanten Unterschied zur Situation im Königreich Preußen auf. Wenngleich beide Länder über Jahrhunderte dem Heiligen Römischen Reich und später dem Deutschen Bund angehörten, gibt es zwischen beiden Staaten markante Unterschiede.

Dies verdient ein umso größeres Interesse, da Berlin in zahlreichen anderen Fragen Wien häufig vorauseilte. Bereits am 17. April 1750 gab König Friedrich II. den „Erlass eines Revidierten General-Privilegiums und Reglements für die Judenschaft im Königreich Preußen" heraus, mit dem er im Rahmen seiner absolutistischen Politik die jüdische Bevölkerung den Interessen des Staates unterwarf, die Zahl der tolerierten Familien erhöhte und den reichsten unter ihnen den Aufenthalt in Städten gestattete. Dies hatte schließlich zur Folge, dass mehr als die Hälfte der annähernd 5.000 brandenburgischen Juden in Berlin lebte. Auch sollte sich die Zahl von Personen jüdischen Glaubens im Lande schrittweise erhöhen, wobei nach der Teilung Polens die Zahl der Juden markant anstieg. Mit Blick auf die Rechtsstellung der Juden damals besaß das Emanzipationsedikt vom 11. März 1812 grundlegende Bedeutung, da es den Juden ermöglichte, die preußische Staatsbürgerschaft zu erlangen. Es handelte sich freilich nicht um eine vollständige rechtliche Gleichstellung wie in Frankreich bzw. in Süddeutschland, im Vergleich zur Situation in anderen europäischen Ländern (einschließlich Österreichs) stellte das Emanzipationsedikt jedoch einen bedeutsamen Fortschritt dar. Das nachfolgende Judengesetz vom 23. Juli 1847 ermöglichte es dann den Juden Ämter zu bekleiden (mit Ausnahme jener, denen eine jurisdiktive, polizeiliche oder exekutive Rechtsgewalt oblag) und sie konnten darüber hinaus Universitätsprofessoren in den Bereichen Medizin, Mathematik, Naturwissenschaften, Geographie sowie Sprachwissenschaft werden. Den Prozess der jüdischen Emanzipation krönte das Gesetz über die rechtliche Gleichstellung des Glaubens vom Juli 1869, das nicht allein in Preußen verkündet wurde, sondern zugleich in allen Staaten des Norddeutschen Bundes.

Im Verlaufe der ersten Hälfte des 19. Jahrhunderts kam es auch in Preußen zu einer Regelung der Nobilitierungsstrategien. Im Unterschied zu anderen Staaten des untergegangenen Heiligen Römischen Reiches konnte in diesem Land die Verleihung von Adelstiteln auf eine ziemlich lange Tradition zurückblicken. Die Hohenzollern hatten seit dem Beginn des 17. Jahrhunderts Adelstitel konfirmiert und als brandenburgische

1 Vgl. Županič, Jan - Fiala, Michal: Nobilitas Iudaeorum. Židovská šlechta středni Evropy v komparatiuni perspective [Nobilitas Iudaeorum. Jüdischer Adel Mitteleuropas in der komparativen Perspektive], Praha 2017. 
Markgrafen und Kurfürsten solche verliehen; als das Herzogtum Preußen jedoch (seit 1657 souverän) im Jahre 1701 zum Königreich aufstieg, nobilitierten sie ausschließlich nur auf der Grundlage ihrer königlichen Rechtsgewalt. ${ }^{2}$ Und auch wenn man niemals verschwenderisch mit der Vergabe von Adelstiteln umging, lässt sich deren Nobilitierungspolitik keineswegs als repressiv bezeichnen.

In einer Hinsicht unterschied sich das Preußen des 19. Jahrhunderts deutlich von Österreich und den süddeutschen Staaten: zu Nobilitierungen kam es nahezu ausschließlich auf der Grundlage eines herrscherlichen Erlasses. Ein systematisierter Adelsstand, verbunden mit Staatsdienst auf zivilem bzw. militärischem Gebiet, wie wir ihn in Württemberg oder Österreich antreffen, existierte hier nicht. Die Einführung eines einfachen Adelsstandes erfolgte hier jedoch sehr spät. Sie war lediglich mit einer einzigen, nur in Ausnahmefällen erteilten Dekorierung verbunden, nämlich der höchsten preußischen Auszeichnung: dem Hohen Orden vom Schwarzen Adler. Diesen gab es nur in einer Klasse, und bis zur Mitte des 19. Jahrhunderts wurde er ausnahmslos Reichsfürsten und Angehörigen alter Adelsfamilien verliehen, die mindestens acht adelige Vorfahren nachweisen und das 30. Lebensjahr erreicht haben mussten. Darüber hinaus handelte es sich nicht um eine verdienstvolle Dekorierung im klassischen Sinne, wie etwa im Falle des Leopoldordens oder des Verdienstordens der bayerischen Krone, sondern um einen einheimischen, primär für Mitglieder der Herrscherdynastie, deren unmittelbare Mitarbeiter und Höflinge bestimmten Orden. ${ }^{3}$ Der Nobilitierungsparagraph lag mit Blick auf seine Bestimmungen erst am 20. Februar 1848 vollständig vor, als König Friedrich Wilhelm IV. dessen Verleihung an nichtadelige Personen ermöglichte. Diese erhielten nunmehr zusammenmit dem Orden auch den erblichen Adelstitel. ${ }^{4}$

Wenn wir einen Blick auf die Sozialstruktur der Neuadeligen werfen finden wir in Preußen ebenso wie in Österreich eine hohe Zahl nobilitierter Offiziere, und zwar ungeachtet der Tatsache, dass es für diese einen systematisierten Adelsstand nicht gab. ${ }^{5}$ Diese Situation hing eng mit der außerordentlichen Rolle zusammen, die die Armee im preußischen Staat spielte. Diese bildete nämlich nicht allein eine Garantie für die Verteidigung des Staates, sondern verkörperte das machtpolitische Instrument seines Aufstiegs. ${ }^{6}$ Das von Friedrich dem Großen eingeführte Prinzip Durch den Degen wird Einer

2 Gritzner, Maximilian (Adolf Maximilian Ferdinand), Chronologische Matrikel der Brandenburgisch-Preußischen Standeserhöhungen vom 1600-1873, Berlin 1874, S. 3 f.

3 Diese Orden existierten selbstverständlich auch in anderen Monarchien. In Österreich handelte es sich um den Orden vom Goldenen Vlies, in England um den Hosenbandorden und in Dänemark um den Elefanten-Orden.

4 Für den gesamten Zeitraum der Existenz dieses Ordens im Königreich Preußen (von Januar 1701 bis November 1918) wurde dieser in 1341 Fällen verliehen. In der übergroßen Mehrzahl der Ordensträger handelte es sich um Angehörige der Herrscherfamilien sowie Nachfahren des alten Adels. Vgl. Hengst, Hermann, Die Ritter des Schwarzen Adlerordens. Biographisches Verzeichnis sämtlicher Ritter des Hohen Ordens vom Schwarzen Adler von 1701 bis 1900, Berlin 1901.

5 Kučera, Rudolf: Staat, Adel und Elitenwandel. Die Adelsverleihungen in Schlesien und Böhmen 1806-1871 im Vergleich, Göttingen - Bristol, CT, USA, 2012, S. 65 ff. Die vom Autor vertretene Meinung, in den Jahren 1814, 1822 und 1823 hätten ausschließlich Offiziere den Adelstitel erhalten, steht im Widerspruch zu Gritzners Evidenz preußischer Nobilitierungen. Gritznet, M.: Chronologische Matrikel, S. 77-78, 86-87.

6 Kučera, R.: Staat, Adel und Elitenwandel, S. 66. 
zum Edelmann, sonst nicht, ${ }^{7}$ galt zwar im 19. Jahrhundert nicht mehr, dennoch wurden Offiziere bei der Verleihung von Adelsprädikaten bevorzugt. Dies geschah etwa dergestalt, dass ein Großteil von ihnen nicht die relativ hohen Nobilitierungstaxen bezahlen mussten, sondern lediglich eine Abgabe für das Diplom. ${ }^{8}$

Die finanzielle Seite spielte nämlich bei den preußischen Nobilitierungen eine nicht zu vernachlässigende Rolle. Im Unterschied zu Österreich kam es hier zur Verleihung eines Titels ohne Taxe (insbesondere bei der Zivilbevölkerung) nur in Ausnahmefällen und die Höhe der Gebühren überstieg diejenigen in der Donaumonarchie in beträchtlichem Maße. In Österreich blieben darüber hinaus die Erhebungstaxen seit dem Jahre 1840 unverändert, ${ }^{9}$ während sie in Preußen sukzessive stiegen. An der Wende vom 19. zum 20. Jahrhundert zahlte in Österreich eine in den einfachen Adelsstand erhobene Einzelperson 1.050 Gulden (2.100 Kronen) für eine Nobilitierung sowie 165 Gulden (330 Kronen) für den dazugehörigen Brief, was nach dem damaligen Kurs annähernd 2.066 Mark ausmachte; in Preußen kostete der gleiche Titel das Dreifache: zur Taxe in Höhe von 3.600 Mark kamen nämlich noch die sog. Stempelsteuer in Höhe von 600 (seit dem Jahre 1909 bereits 1.200) Mark sowie die Kosten für das Adelsdiplom in Höhe von 600 Mark hinzu, was in der Umrechnung 5.539 (bzw. 6.514) Kronen ausmachte. ${ }^{10}$ Eine solche Ausgabe hätte sich ein Großteil der Neuadeligen in der Donaumonarchie (vor allem aus den Reihen der Beamten und Intellektuellen) nicht leisten können. Wie die nachfolgende Grafik zeigt, wich auch die Zusammensetzung des preußischen Neuadels von jener Struktur in Österreich ein wenig ab. ${ }^{11}$

7 Mit diesen Worten reagierte der Monarch angeblich auf die Bitte eines schlesischen Großgrundbesitzers um Erhebung in den Adelsstand. Zitiert nach: Grünhagen, Colmar: Der schlesische Adel vor hundert Jahren im Lichte der öffentlichen Meinung, in: Zeitschrift des Vereines für Geschichte und Alterthum Schlesiens, Jg. 30 (1896), S. 6.

8 Vgl. die Nobilitierung des Generalleutnants Karl Berthold Sigismund Ribbentrop (1884) bzw. des Vizeadmirals und Staatssekretärs des Reichsmarineamts Alfred Peter Friedrich Tirpitz (1900). In: Geheimes Staatsarchiv Preußischer Kulturbesitz, Berlin - Dahlem (weiter nur: GStA), I. HA Rep. 176 Heroldsamt, Nr. 7713 (Ribbentrop); ebd. Nr. 9771 (Tirpitz).

9 Taxpatent vom 27. Januar 1840, § 137.

10 Der Wechselkurs von österreichisch-ungarischer Krone gegenüber der deutschen Mark lag im Jahre 1912 im Rahmen des Goldstandards bei 1,176 Kronen zu 1 Mark. Otto, Carl, Der Haussekretär, Berlin 1913, S. 485, 3. Umschlagseite; Kalm, Harald von: Das preußische Heroldsamt (1855-1920). Adelsbehörde und Adelsrecht in der preußischen Verfassungsentwicklung, Berlin 1994, S. 74-75; Frank-Döfering, Peter: Adelslexikon des Österreichischen Kaisertums 1804-1918, Wien-Freiburg-Basel 1989, S. 652-655; Binder-Krieglstein, Reinhard: Österreichisches Adelsrecht. Von der Ausgestaltung des Adelsrechts der cisleithanischen Reichshälfte bis zum Adelsaufhebungsgesetz der Republik unter besonderer Berücksichtigung des adeligen Namensrechts, Frankfurt am Main 2000, S. 120; Hertz-Eichenrode, Dieter: Wilhelminischer Neuadel? Zur Praxis der Adelsverleihung in Preußen vor 1914, in: Historische Zeitschrift, Bd. 282, Heft 3 (Juni 2006), S. 653-654.

11 Erstellt nach: Stein, Hans Konrad: Der preußische Geldadel des 19. Jahrhunderts. Untersuchungen zur Nobilitierungspolitik der preußischen Regierung und zur Anpassung der oberen Schichten des Bürgertums an den Adel, Dissertation an der Universität Hamburg), Hamburg 1982, S. 401. 


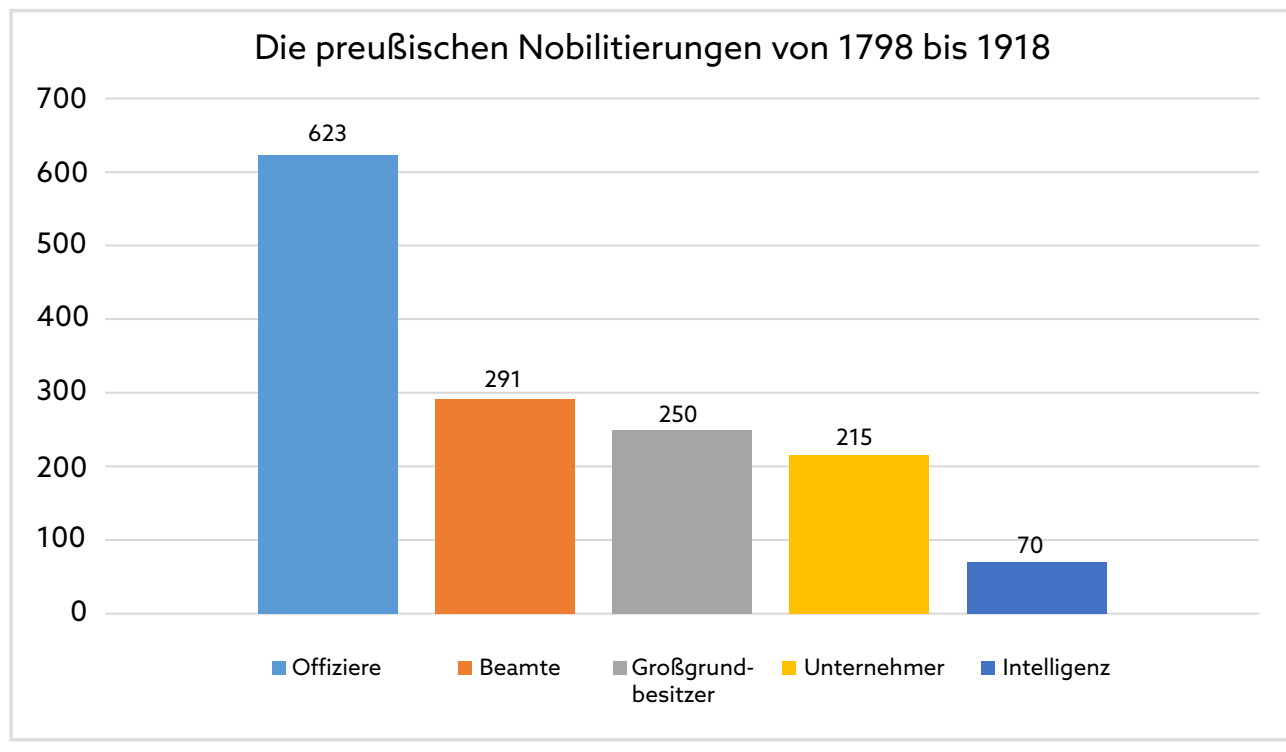

Angesichts des Verhältnisses zwischen Nobilitierungen militärischer und ziviler Personen (623 : 826) scheint die Behauptung von einem Übergewicht von Neuadeligen aus den Reihen der Offiziere übertrieben, doch sollte man sich vergegenwärtigen, dass im Unterschied zu den übrigen Nobilitierten die Repräsentanten der Armee eine kompakte Gruppe bildeten. Für die Zivilbevölkerung Preußens war der Aufstieg in den Adelsstand weitaus schwieriger. Eindeutig bevorzugt wurden bei Nobilitierungen Großgrundbesitzer und Beamte, die Zahl der nobilitierten Unternehmer und Vertreter der Intelligenz ${ }^{12}$ fiel wesentlich geringer aus und erreichte bei weitem nicht jenen Anteil, den diese Gruppe unter den Neuadeligen in Österreich ausmachte. ${ }^{13}$

Wie aus den beiden nachfolgenden Grafiken, die die Entwicklung der preußischen Nobilitierungen von der Mitte des 19. Jahrhunderts bis zum Untergang der Monarchie verdeutlichen - die erste Grafik allgemein, die zweite in einzelnen Dekaden -, repräsentierten Offiziere, Beamte und Großgrundbesitzer im Längsschnitt die sozialen Hauptgruppen, aus denen sich der neue Adel rekrutierte. Der Anteil der Unternehmer begann erst seit dem ausgehenden 19. Jahrhundert zu wachsen. ${ }^{14}$

12 Unter die Intelligenz (Bildungsadel) reiht K. Stein die gebildeten Zivilschichten (Künstler, Wissenschaftler, Juristen, Ärzte usw.) ein, die nicht zu den Beamten zählten, ebenso Intellektuelle aus vermögenden und gebildeten Bürgerfamilien, denen ein Großgut gehörte. Ebd. S. 399.

13 Ebd., S. 11-14, 23-38.

14 Ebd., S. 401. 

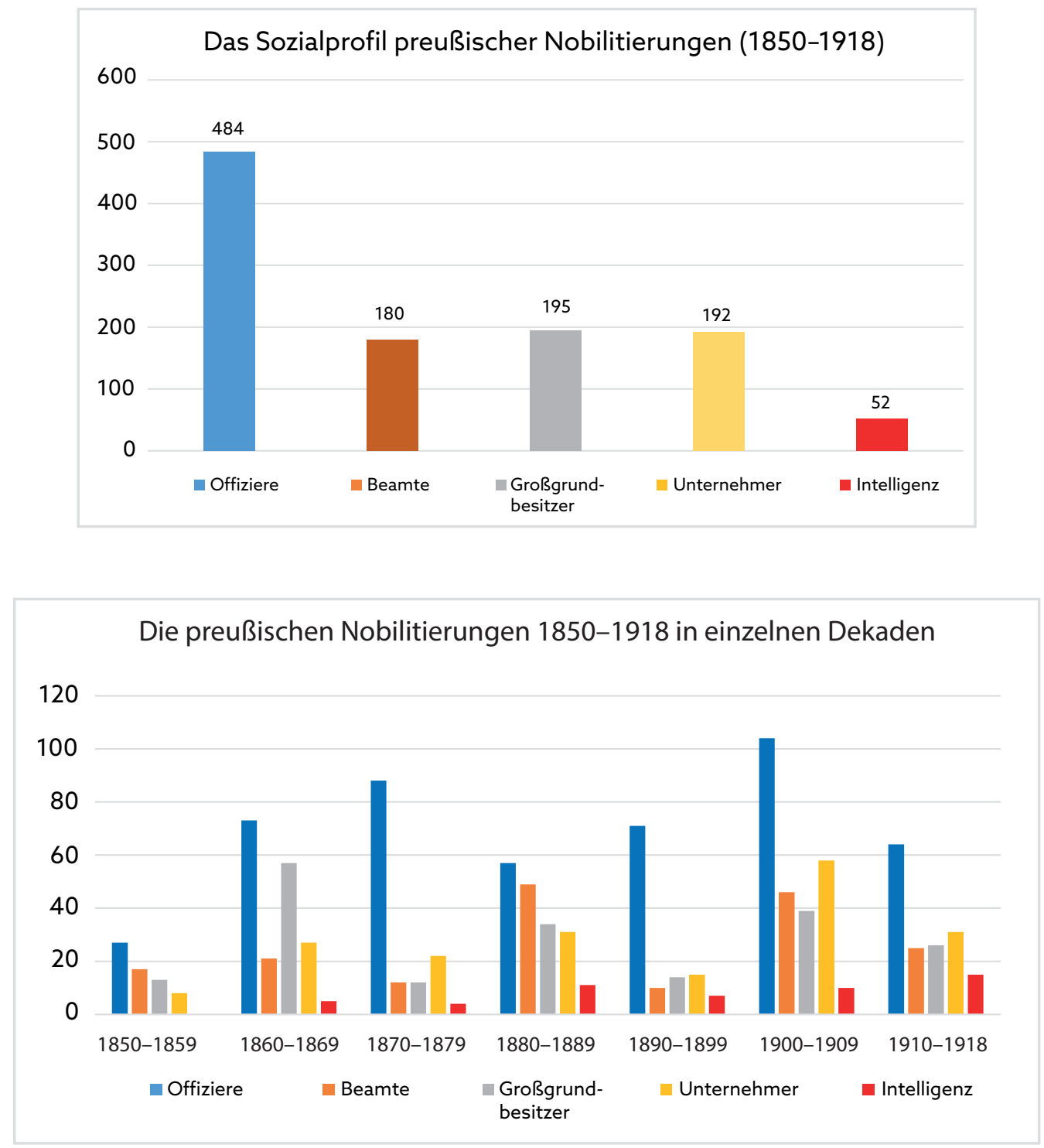

Ein interessanter Versuch für eine Reform der preußischen Nobilitierungspolitik ist mit dem Regierungsantritt König Friedrich Wilhelms IV. verbunden, der bereits kurz nach seiner Thronbesteigung im Jahre 1840 mehrere Schritte unternahm, um den preußischen Adel nach englischem Vorbild umzuformen. Seine Pläne hatten ältere Wurzeln, die bis in die zwanziger Jahre des 19. Jahrhunderts zurückreichten, als der (nie realisierte) Plan zur Bildung eines neuen Adels aus reichen Großgrundbesitzern entstand. Im Jahre 1841 konstatierte der preußische Innenminister Gustav von Rochow, dass die einheimische Erb-Elite ernsthaft bedroht sei. Er machte darauf aufmerksam, dass deren Güter oftmals ziemlich klein und wenig ertragreich seien, um diese zu nutzen, so dass 
viele diese verkauften. Dadurch gehe jedoch die Bindung zum Boden verloren, der Adel verliere seinen sozialen Status und deren weitere Existenz ähnele derjenigen des Bürgertums. Dieser kleine und verarmte Adel orientierte sich Rochow zufolge darüber hinaus einseitig auf den Staatsdienst, den er außerdem für seine Söhne auswähle. Aus finanziellen Gründen vermöge er jedoch häufig nicht den Söhnen eine ordentliche Ausbildung zukommen zu lassen, so dass ein Teil von ihnen bei dieser Karriere scheitere und sich gezwungenermaßen seinen Lebensunterhalt als Handwerker oder Gewerbetreibender verdienen müsse. Dies würde natürlich das Gewicht des Adels innerhalb der Gesellschaft mindern. ${ }^{15}$

Rochows Worte fanden ein positives Echo bei dem romantisch und konservativ denkenden Friedrich Wilhelm IV., der eine Wiederherstellung der gestörten Harmonie zwischen den Ständen herbeisehnte und seine Politik dergestalt ausrichtete. Bei den Nobilitierungen bevorzugte er deshalb Großgrundbesitzer bürgerlicher Herkunft, wobei der Besitz einer adeligen Herrschaft häufig die Bedingung für den Erwerb des Titels bildete. Das Hauptmotto dieser Idee fasste im Jahre 1842 Ernst von Bülow-Cummerow wie folgt zusammen: „Wenn eine gewisse Konsequenz in dem System festgehalten werden soll, [...] so müsste überhaupt der Adel mit dem Besitz von Grund und Boden verwachsen bleiben und umgekehrt, der Besitz von Grund und Boden und die Rechte des ersten Standes wiederum den Besitzer adeln, solange dieser und seine Nachkommen sich im Besitz der Güter erhalten." 16

Adelsprädikate sollten daher nicht Familien erteilt, sondern innerhalb von Familien vergeben werden, d. h. unmittelbar den Besitzern der neu eingerichteten Fideikommisse. Aus diesem Grunde schlug auch ein Teil der königlichen Ratgeber vor, in Preußen den Adelstitel ad personam einzuführen, auch wenn man dies für Deutschland als ungewöhnlich betrachtete. Die hierfür vorgebrachten Gründe unterschieden sich jedoch stark von jenen, die zum Entstehen einer solchen Institution in den süddeutschen Staaten geführt hatten. Der Adelstitel ad personam sollte in Preußen vor allem für Offiziere unterer Ränge gelten, die nicht für sich selbst und schon gar nicht für ihre Nachkommen eine standesgemäße Existenz zu sichern vermochten und bei denen zudem das Risiko eines sozialen Abstiegs bestand. Bei Beamten wiederum wurde ein solches Vorgehen nicht ins Auge gefasst. Diese sollten überhaupt nicht in den Adelsstand erhoben werden, weil nach Meinung der Initiatoren der Reform den Beamten durch ihre Funktion ohnehin Privilegien und Anerkennung entgegengebracht wurden. ${ }^{17}$

Zur Verleihung personengebundener Adelstitel für Offiziere kam es am Ende nicht. Ebenso wurden später die Voraussetzungen für die Schaffung eines Fideikommisses gemildert. Auf der anderen Seite erhöhte der Besitz eines Großgutes, verbunden mit dem Versprechen zur Einrichtung von Fideikommissen, die Chancen von Antragstellern auf eine Nobilitierung bis zum Untergang der Monarchie in bedeutendem Umfang.

15 Reif, Heinz: Adel, Aristokratie, Elite. Sozialgeschichte von oben, Berlin - Boston 2016, S. 90-91.

16 Zitiert nach: Bülow-Cummerow, Ernst von: Preußen. Seine Verfassung, seine Verwaltung, sein Verhältnis zu Deutschland, Teil I, Berlin 1842, S. 97. Vgl. des Weiteren Kučera, R.: Staat, Adel und Elitenwandel, S. 73-75; Reif, H.: Adel, Aristokratie, Elite, S. 86-87, 91-92. 
Die Bildung derartiger Güter erwies sich nämlich für beide Seiten als vorteilhaft - zum einen sicherte deren Existenz dem Familienoberhaupt und auch nachfolgenden Generationen einen angemessenen Lebensstandard, zum anderen wurde für deren Begründung eine relativ hohe Abgabe fällig, die in die Staatskasse floss. ${ }^{18}$ Seit dem Jahre 1843 wurden darüber hinaus hohe Adelstitel (Freiherr, Graf, Fürst und Herzog) direkt an die Einrichtung eines Fideikommisses gebunden. Im Unterschied zu Österreich standen derartige Titel - sofern nicht anders festgelegt - ausschließlich dem Familienoberhaupt zu, während die übrigen Mitglieder lediglich zum einfachen Adel gehörten. ${ }^{19}$ Allerdings machte man bei der Erhebung in den Stand der Feldherren häufig eine Ausnahme von dieser Regel. ${ }^{20}$

Gerade aus diesem Grund lag die Zahl der neuen Fideikommisse außerordentlich hoch und deren Eigentümer wurde der gewöhnliche Adel. ${ }^{21}$ Auch die Fläche der preußischen Fideikommisse war beträchtlich. Sie betrug im Durchschnitt 2-3.000 Hektar, wobei deren Preis sich bei etwa einer Million Mark bewegte. Darüber hinaus existierten auch neuadelige Fideikommisse von mehr als 10.000 Hektar. ${ }^{22}$ Im Verlaufe des wachsenden Nationalismus in der zweiten Hälfte des 19. und zu Beginn des 20. Jahrhunderts spielten (oder sollten diese eher spielen) die Fideikommisse eine wichtige Rolle bei der Germanisierung der überwiegend polnischen Gebiete Oberschlesien, Westpreußens und des Posener Landes, wobei das Versprechen ihrer Einrichtung auf dem genannten Territorium einen positiven Einfluss auf die Gewährung der Bitte um Nobilitierung ausübte..$^{23}$

$$
* * *
$$

Wenngleich die Zahl der vergebenen Adelsprädikate in Preußen im gesamten langen 19. Jahrhundert allmählich stieg, lag deren Höhe dennoch weit unter jener in der Donaumonarchie. In den Jahren 1870/71-1918 wurden in Preußen insgesamt 1.315 Nobilitierungen erteilt, von denen 1.094 (83 Prozent) auf den einfachen Adel entfielen. ${ }^{24}$ In diese Zahl fallen jedoch auch die Konfirmierung von Titeln sowie die Übertragung von

18 Mitte der zwanziger Jahre des 19. Jahrhunderts betrug diese mindestens 2500 Thaler. In Ausnahmefällen konnte diese Summe jedoch durch den Monarchen verändert werden. Ebd., S. 84 .

19 In einigen Fällen wurden höhere Titel ausschließlich ad personam vergeben. Vgl. den weiter unten geschilderten Fall des Albert von Goldschmidt-Rothschild.

20 Stein, H. K.: Der preußische Geldadel, S. 11.

21 Hierin lag ein großer Unterschied im Vergleich zur Donaumonarchie, in der die Begründung der Fideikommisse de jure möglich war, sich in Wahrheit jedoch nur auf altadelige Herrenfamilien beschränkte. Županič, Jan: Nová šlechta Rakouského císařství [Der Neuadel des Kaiserreichs Österreich], Praha 2007, S. 251-256.

22 Stein, H.K.: Der preußische Geldadel, S. 106-111.

23 Vgl. die weiter unten aufgeführten Fälle der Familien Goldschmidt-Rothschild bzw. Friedlaender-Fuld.

24 Allein in Österreich (bzw. Cisleithanien) erfolgten in den ersten fünfzig Jahren der Regierung Franz Josefs I. (1848-1898) 4.651 Standeserhebungen nichtadeliger Personen. Witting, Johann Baptist: Statistik der Standeserhöhungen während der Regierung Seiner Majestät des Kaisers Franz Josef I., in: Festschrift zum fünfzigjährigen Regieruns-Jubiläum (1848-1898) Seiner kaiserlichen und königlichen apostolischen Majestät Franz Josef I. (Hrsg. von Historischen Vereinen Wiens im Selbstverlage des Vereines für Landeskunde von Niederösterreich), Wien 1898, S. 59-91. 
Prädikaten mit Hilfe von Adoptionen. Die Zahl der Nobilitierungen selbst fiel geringer aus, deren tatsächliche Zahl wird auf 855-857 geschätzt. ${ }^{25}$

Auf die endgültige Ausformung der preußischen Adelsgemeinde und deren Politik übte die dortige Nobilität einen großen Einfluss aus, konkret die kleinadeligen Gutsherren und Junker. ${ }^{26}$ Wenngleich sich die Auffassungen ihrer Repräsentanten unterschieden, stimmten doch alle im Grunde in einer Sache überein: Ein grundlegendes Identifikationsmerkmal des Adels musste ein umfangreicher Grundbesitz sein. Ein Großteil der Junker lehnte zudem eine weitere Zunahme der Nobilitierungen ab, zumal die Erhöhung der Zahl der Adeligen deren bisherige exklusive gesellschaftliche Stellung gefährden konnte. Aus diesem Grunde existierte in den Jahren 1843-1863 eine Vorschrift, die die Vererbung eines höheren Titels von der adeligen Herkunft beider Eltern abhängig machte.

Einen großen Einfluss bewahrte sich der Familienadel darüber hinaus im Jahre 1855 durch die Institutionalisierung des Heroldsamts, welches die oberste Instanz in Sachen des Adelsrechts verkörperte. Seine Rechtsgewalt erhielt es vom Ministerium des Königshauses. ${ }^{27}$ Das Heroldsamt griff allerdings nicht allein in juristische Angelegenheiten ein, seine Repräsentanten beeinflussten auch die gesamte Adelspolitik in entscheidendem Maße. Dabei war es keine Seltenheit, dass deren Vertreter selbst den Vorschlägen des Monarchen widersprachen, was beispielsweise im Österreich Kaiser Franz Josefs nur schwer denkbar schien. Ein negatives Verhältnis hatte das Heroldsamt insbesondere gegenüber Nobilitierungen von Personen, die keinen evangelischen Glaubens besaßen in erster Linie Juden. Für das Amt (und notwendigerweise auch für einen nicht unerheblichen Teil des preußischen Adels) war dabei nicht ausschlaggebend, ob diese Einzelpersonen nun dem Judentum angehörten oder lediglich eine jüdische Herkunft besaßen. Deren Standeserhebung galt als nicht wünschenswert. Nach dem sehr kurzen Zeitraum eines relativen Liberalismus um 1860 folgte eine ausgesprochen restriktive Politik, die sich gegen Personen richtete, die sich deshalb häufig um Adelsprädikate in anderen deutschen Staaten bemühten. Die Konfirmierung derartiger Nobilitierungen erwies sich aber auch so als eine schwierige Angelegenheit. ${ }^{28}$

Die Auffassung des Heroldsamts gegenüber den Nobilitierungen von Juden lässt sich sehr deutlich aus dem Memorandum entnehmen, das im Jahre 1895 der spätere Chef

25 Zu der Zahl 857 gelangten Herzt-Eichenrode, D.: Wilhelminischer Neuadel?, S. 654 und CECIL, Lamar, The Creation of Nobles in Prussia, 1871-1918, I. American Historical Review, Vol. 75, No. 3 (Feb., 1970), S. 759-761. Stein, H. K.: Der preußische Geldadel, S. 401 ermittelte die Zahl 855.

26 Zu dieser Frage vgl. Kučera, R.: Staat, Adel und Elitenwandel, S. 71-72.

27 Das Heroldsamt wurde unter dem Namen Oberheroldsamt bereits im Jahre 1706 gegründet, doch stellte es in den Jahren 1713/14 seine Tätigkeit wieder ein. Dessen Kompetenzen übernahmen schrittweise zahlreiche Organe, ehe in den Jahren 1810-1822 die Staatskanzlei als Vorgängerin des Amtes des Ministerpräsidenten (eingerichtet in den Jahren 1848/50) zur obersten Instanz für das Adelsrecht aufstieg. In den Jahren 1822-1848 übernahm dessen Rechtsgewalt das Ministerium des Königshauses Preußen, 1848-1854 richtete das Ministerium für Inneres und Justiz das Heroldsamt wieder ein. Kalm, H. von: Das preußische Heroldsamt, S. 18-34.

28 Vgl. exemplarisch Andrian-Wernburg, Klaus Freiherr von: Die Nobilitierung preußischer Untertanen in Sachsen-Coburg und Gotha, in: Archivalische Zeitschrift, 75. Jg., 1979, S. 1-15. 
dieser Institution, Hans von Borwitz, für Wilhelm II. vorbereitete und das die Bitte auf Erhebung in den Adelsstand durch den Bankier und Geheimen Kommerzrat Ernst Mendelssohn-Bartholdy beinhaltete. Wenngleich bereits Ernsts Großvater Abraham Mendelssohn (1776-1835) im Jahre 1822 zum Protestantismus konvertiert war und bei dieser Gelegenheit den Namen Mendelssohn-Bartholdy angenommen hatte, blieb der Antragsteller für Borwitz Jude. Er lehnte die Bitte ab und betonte, dass die Verleihung von Adelstiteln an solche Personen nicht im Interesse Preußens läge. „Die Zahl der geadelten Familien jüdischer Abstammung ist durch die fast durchgehend außerhalb Preußens geübte Nobilitierung solcher Geschlechter bereits eine sehr bedruckende. Wir können auch feststellen, dass einige dieser Familien durch Verschwägerung, Erwerbung von Grundbesitz und hiervon sich schließende Aufgabe der früheren geschäftlichen Thätigkeit äußerlich in dem Adel aufgegangen zu sein schienen." Borwitz zufolge war es notwendig, dass diese „Börsen-Nobilität“ wahre, für die Gewinnung des Titels unerlässliche Verdienste vorzeige. Seine Aufzeichnungen beendete mit den Worten: „Unser christlicher Adel deutscher Nation nimmt aber seit dem letzten Vierteljahrhundert schon derartig viel fremdes Blut in sich auf, das es dahinsteht, ob diese Blutmischung nicht endlich sein Wesen wirkt verändern müssen. " 29

$$
* * *
$$

Interesse verdient, dass in Preußen der Antisemitismus derart verbreitet und der Widerstand gegen Nobilitierungen von Juden dermaßen extrem war, wenngleich deren Zahl viermal niedriger als in Österreich ausfiel, wo wir ein derartiges Verhalten nicht registrieren können. ${ }^{30}$ Zur ersten Nobilitierung eines jüdischen Konvertiten kam es hier darüber hinaus (für deutsche Verhältnisse) ziemlich früh - während der napoleonischen Kriege. In den Adelsstand erhoben wurde der einflussreiche Bankier und Besitzer der Großhandlung Delmar E Comp. Ferdinand Moritz Delmar (1781-1858) ${ }^{31}$, der Preußen mit einem Darlehen in Höhe von 1,5 Millionen Gulden maßgeblich bei der Bezahlung von Reparationen nach dem Tilsiter Frieden im Jahre 1807 unterstützt hatte. Delmar stammte aus der Familie Lewy, die sich bereits seit mehreren Generationen mit Finanzgeschäften beschäftigt hatte ${ }^{32}$, für seinen gesellschaftlichen Aufstieg erwiesen sich zwei

29 Zitiert nach: Bericht des Beamten (1900-1918 Chefs) des Heroldamts Hans von Borwitz vom 22.10.1895 über die Nobilitierung des Bankiers Ernst Mendelssohn-Bartholdy (GStA, I. HA Rep. 176 Heroldsamt, Nr. 6168 (Mendelssohn-Bartholdy 1896). Ernst wurde schließlich durch Wilhelm II. am 17. 2. 1896 in den Adelsstand erhoben. Die Unterstreichungen stammen vom Autor des Memorandums.

30 Nach der Volkszählung aus dem Jahre 1900 lebten in Preußen 34468307 Menschen, von denen 392322 Juden waren. Ottưv slownik naučný, Bd. XX., S. 855-856.

31 Zu Delmar vgl. NDB, Bd. 3, S. 588-589; Schnee, Heinrich: Die Nobilitierung der ersten Hoffaktoren. Zur Geschichte des Hofjudentums in Deutschland, in: Archiv für Kulturgeschichte, Bd. 43/1961, S. 94-95; Kučera, R.: Staat, Adel und Elitenwandel, S. 103; Županič, Jan: Židovská šlechta podunajské monarchie. Mezi Davidovou hvězdou a křižem [Der jüdische Adel der Donaumonarchie. Zwischen Davidstern und Kreuz], Praha 2012, S. 61.

32 Die Familie stammte aus Posen, Delmar selbst wurde jedoch in Charlottenburg bei Berlin geboren, wo sein Vater Moses Salomon Levy (1757-1813), genannt Chalfan, im Jahre 1785 von Friedrich dem Großen ansonsten ausschließlich christlichen Kaufleuten zustehende Privilegien erhielt. Mit dem preußischen 
Dinge als wesentlich. Zunächst ging es um Konvertierungen zum Luthertum, zu dem Delmar gemeinsam mit seinem Bruder Samson Moses (nach 1781-nach 1829) ${ }^{33}$ im Jahre 1809 übergetreten war. Bei dieser Gelegenheit legte er seinen bisherigen Namen Salomon Moses Levy ab und nannte sich fortan Ferdinand Moritz Delmar. Den zweiten wichtigen Umstand machten seine engen Beziehungen zu den Franzosen aus, die ihn unverblümt unterstützten. Der Bankier gehörte nämlich zu den führenden Persönlichkeiten des pro-napoleonischen Flügels im Königreich Preußen und seine Nobilitierung, die die führenden preußischen Beamten vehement abgelehnt hatten, setzte niemand anders als der französische Gesandte Graf Saint Marsan durch. Auf dessen Fürsprache hin wurde Delmar im Jahre 1810 zunächst in den Adelsstand und nachfolgend auch in denjenigen eines Freiherrn erhoben. ${ }^{34}$ Nach Napoleons Niederlage ließ sich Delmar in Paris nieder, wo er auch verstarb. Im nachfolgenden Vierteljahrhundert wurde kein Jude bzw. jüdischer Konvertit in Preußen nobilitiert.

Ein kurzer Zeitraum von Veränderungen ist erst mit der Übernahme der Regentschaft durch den Prinzen Wilhelm im Jahre 1858 verbunden. Zuerst erhob dieser am 16. Mai 1859 den Berliner Bankier und Mitbesitzer der Herrschaft Reinfeld (Bierzwnica) in Hinterpommern Georg Moritz Oppenfeld (1793-1861), der bis zu seiner Konvertierung im Jahre 1822 den Namen Moses Oppenheim geführt hatte ${ }^{35}$, in den Adelsstand, nachfolgend erteilte er am 18. Oktober 1861 aus Anlass seiner Krönung in Königsberg den gleichen Titel auch dessen Bruder Carl Daniel (1800-1861), ebenfalls ein Konvertit.

Georg Moritz Oppenfeld hatte sich dabei um den Adelstitel - ursprünglich allerdings nur für seinen Sohn Carl Friedrich (1818-1871) - seit den vierziger Jahren bemüht, seine Bitte jedoch war wiederholt auf Ablehnung gestoßen. Interesse verdienen die dabei vorgetragenen Argumente. Wilhelm von Bonin, Oberpräsident der Provinz Pommern und zugleich Präsident des Regierungsbezirkes in Stettin, in dem Oppenfelds Gutsherrschaft lag, hatte auf die Bitte um ein Adelsprädikat angemerkt, der junge Carl Friedrich sei zwar eine respektierte Persönlichkeit, doch würden sich bei ihm, noch deutlicher als bei seinem Vater, jüdische Verhaltensweisen zeigen - sowohl in seinen Gebärden als auch in der Sprache. Dieses physiognomisch begründete Memorandum nahm zwar Berlin nicht zur Kenntnis, doch entsprach es dem gesellschaftlichen Klima der Zeit. ${ }^{36}$

Staat arbeitete bereits Delmars Großvater Salomon Moses Levy (gest. 1778) zusammen, der seit 1761 als Münzfaktor in Berlin wirkte.

33 Nach der Taufe nannte sich dieser Karl August Delmar.

34 Das Datum der Nobilitierung steht nicht genau fest. Um den Titel eines Barons suchte er am 11. 1. 1810 nach. Einer Notiz im Schreiben vom 6. 4. 1810 zufolge unterstützte Delmars Bitte mit einer offiziellen Note Graf Saint Marsan, bei der nachfolgenden Sitzung des königlichen Rates am 10. 5. 1810 stimmte König Friedrich Wilhelm III. dem Gesuch zu. Im Konzept des herrscherlichen Schreibens an Graf zu Dohna vom 14. 7. 1810 wird allerdings vermerkt, er werde Delmar, dem er am 24. 5. 1810 (!) das Adelsprädikat verliehen habe, in den Freiherrenstand erheben. In: GStA, I. HA Rep. 89 Geheimes Zivilkabinett, Nr. 1248 (Delmar). M. Gritzner nennt als Datum der Nobilitierung den 13. 4. 1810 und begründet dies damit, dass die Nachricht über die Erhebung am 22. 9. 1810 veröffentlicht worden sei. Zur Ausfertigung des Majestätsbriefes kam es erst am 11. 6. 1816. Gritzner M.: Chronologische Matrikel, S. 75.

35 Ebd., S. 126, 131.

36 Drewes, Kai: Jüdischer Adel. Nobilitierungen von Juden im Europa des 19. Jahrhunderts, Frankfurt am Main New York 2013, S. 198-200, 394. 
Zur ersten Standeserhebung eines ungetauften Juden kam es in Preußen erst am Ende der ersten Herrschaftsdekade Wilhelms II., als der König im Jahre 1868 dem Geheimen Kommerzrat Abraham Oppenheimer (1804-1878) den Titel eines Freiherrn verlieh. Dabei handelte es sich um einen keinen einfachen Prozess. Oppenheim, der aus einer sehr einflussreichen Familie von Finanziers aus Köln am Rhein stammte, war Besitzer einer bedeutenden Privatbank und dank der Heirat mit Charlotte Beyfus (18111887) auch ein naher verwandter der Familie Rothschild. Um einen Adelstitel hatte er sich bereits im Jahre 1863 bemüht, als er den Wunsch äußerte nobilitiert zu werden. Der Minister des Königshauses, Alexander Graf von Schleinitz, hatte jedoch in einem Brief an Königin Auguste vorgeschlagen, der Antragsteller solle lieber mit dem Komturkreuz des hohenzollernschen Hausordens ausgezeichnet werden. ${ }^{37}$ Von seiner Nobilitierung begann man deshalb erst nach dem Preußisch-Österreichischen Krieg im Zusammenhang mit den außerordentlichen Diensten im Finanzbereich zu sprechen, die er Berlin in den Jahren 1864-1866 erwiesen hatte.

Am 10. November 1866 zeigte Schleinitz dem Innenminister Friedrich Graf zu Eulenburg an, der König habe Oppenheimer die Erhebung in den Adelsstand zugesichert. Er selbst betrachtete die Nobilitierung als außerordentlich problematisch, und zwar keineswegs aus juristischer Sicht, wo er keine Komplikationen sah, sondern mit Rücksicht auf den Charakter des preußischen Adels. Er sprach daher die Empfehlung aus, das Ende der Feierlichkeiten nach Kriegsende abzuwarten.

Eulenburg reagierte auf das Schreiben erst am 26. April des nachfolgenden Jahres. Er führte an, dass er persönlich gegen eine Nobilitierung keinerlei Einwände habe schon allein deshalb, weil Oppenheim kinderlos und die Wahrscheinlichkeit gering sei, dass er eine eigene Familie begründen werde. Oppenheim wäre darüber hinaus nicht der erste jüdische Baron Preußens gewesen, zumal in der Zwischenzeit sein Verwandter, der Bankier Rotschild ${ }^{38}$, preußischer Untertan geworden war. Die gleiche Auffassung vertrat auch der Ministerpräsident Graf Bismarck, die übrigen Minister hingegen wandten sich strikt gegen einen solchen Schritt. Am Ende siegte der König, der am 14. Februar 1868 Oppenheim den Titel eines Barons verlieh.

Die Banken jüdischer Unternehmer spielten nämlich in der Wirtschaft des Landes eine wichtige Rolle, aus diesem Grunde war der Monarch geneigt, deren Eigentümern auch gewisse Privilegien einzuräumen. Viele von ihnen wurden früher oder später dafür mit Orden und dem Titel eines Kommerzrates bzw. Geheimen Kommerzrates entlohnt und Mayer Carl von Rotschild wurde sogar Ende 1867 als erster Jude überhaupt Mitglied der Ersten Kammer (Herrenkammer) des Preußischen Landestages. Ein Adelsprädikat jedoch erhielten Juden lediglich in absoluten Ausnahmefällen.

37 Drewes, K.: Jüdischer Adel, S. 208.

38 Es handelte sich um keine exakte Äußerung. Preußische Untertanen wurden im Ergebnis der preußischen Annexion der Freien Stadt Frankfurt am Main nach dem Deutsch-Österreichischen Krieg drei Söhne des Bankiers Karl Meyer von Rothschild (1788-1855): Mayer Carl (1820-1888), Adolf Carl (1823-1900) und Wilhelm Carl (1828-1901), dessen Tochter gemeinsam mit ihrem Gemahl Maximilian Goldschmidt (1843-1940) die Familie Goldschmidt-Rothschild begründete. Vgl. weiter unten. 
Der zweite - und zugleich für lange Zeit letzte - nobilitierte Jude wurde vier Jahre nach Oppenheim Gerson Bleichröder (1822-1893), Eigentümer des Bankhauses S. Bleichröder, das bereits im Jahre 1803 dessen Vater Samuel (1779-1855) begründet hatte. Dieser war um 1860 zusammen mit der Bank Sal. Oppenheim aus Köln am Rhein bedeutendster Investor in preußische Staatsanleihen und spielte zudem er wichtige Rolle beim Aufbau der deutschen Eisenbahn. In dieser Zeit galt Bleichröder bereits als reichster Mann Preußens und sein Vermögen belief sich auf 100 Millionen Mark. Bleichröder sorgte für die Absicherung der Finanzen zur Führung des Preußisch-Österreichischen sowie des Deutsch-Französischen Krieges und spielte eine wichtige Rolle bei den Reparationsverhandlungen nach der Niederlage Frankreichs im Jahre 1871.

Gerson Bleichröder galt zugleich als sehr schwierige Persönlichkeit, zahlreiche Personen - einschließlich des liberalen Thronfolgers Friedrich Wilhelm (des späteren Friedrich III.) - verhielten sich ihm gegenüber ablehnend. Sein Ehrgeiz war außerordentlich, einige Geschäften und Aktionen, an denen er sich beteiligte, galten als anstößig. ${ }^{39}$ Unter anderem deshalb bildete Bleichröder ein dankbares Ziel antisemitischer Ausfälle in der deutschen Presse. Als ein großer Vorteil Bleichröders erwies sich dessen enge Beziehung zu Otto von Bismarck, für den er de facto als persönlicher Bankier und Vertrauter für Finanzangelegenheiten wirkte.

In den Adelsstand stieg Bleichröder am 8. März 1872 auf, und zwar ohne jegliche Taxe zu bezahlen. ${ }^{40}$ In der Geschichte des preußischen Adels handelte es sich dabei um ein historisches Ereignis: die erste Nobilitierung eines Juden, der nachfahren besaß und damit auch zur Gründung eines jüdischen Adelsgeschlechts beitrug ${ }^{41}$, was mit sichtbarem Stolz die Allgemeine Zeitung des Judentums unterstrich. Die Hoffnungen vieler Juden, dass sich nunmehr das Verhalten des Staates ihnen gegenüber in dieser Hinsicht ändern werde, erwies sich jedoch als trügerisch. Die Reaktionen konservativer Kreise in Preußen waren grundsätzlich ablehnend und in den nachfolgenden drei Dezennien erhielt nicht ein einziger Jude in Preußen ein Adelsprädikat. ${ }^{42}$

$$
* * *
$$

In dieser sehr kurzen liberalen Periode, die wir durch die Zeitspanne zwischen dem Preußisch-Österreichischen Krieg im Jahre 1866 und dem Ausbruch der Wirtschaftskrise 1873 begrenzen können, kam es in Preußen auch zu einer Konfirmierung von ausländischer Adelstitel von weiteren sechs Juden, die de facto deren Einreihung unter

39 Sehr widersprüchlich ist beispielsweise Bleichröders Anteil an der sog. Arnim-Affäre. Vgl. Stern, Fritz Richard: Gold und Eisen. Bismarck und sein Bankier Bleichröder, München 2008, S. 323-371.

40 GStA, I. HA Rep. 176 Heroldsamt, Nr. 418 (Bleichröder 1872).

41 Aus den Materialien des Heroldsamts geht hervor, dass Bleichröders Sohn James (1859-1937) später zum Protestantismus konvertierte. Zum gleichen Schritt entschloss sich aus Heiratsgründen auch Gersons Tochter Elsa (1865-1936). Bei zwei weiteren Söhnen konnte eine eindeutige Bestätigung für die Konvertierung nicht zweifelsfrei ermittelt werden. GStA, I. HA Rep. 176 Heroldsamt, Nr. 418 (Bleichröder 1872); Gaugusch, Georg, Wer einmal war. Das jüdische Grossbürgertum Wiens 1800-1938, A-K, Wien 2011, S. 203. 
den preußischen Adel bedeuteten. Als charakteristisch hierbei erwies sich, dass fünf der Nobilitierten im Bankwesen tätig waren, während der sechste Neuadelige als Großhändler und Besitzer einer Textilfabrik agierte.$^{43}$ Eine bedeutende Rolle bei der Anerkennung dieser Nobilitierungen spielte unbestritten die Tatsache, dass die in den Adelsstand erhobenen Personen die Titel in Staaten erhielten, die die preußische Regierung in dieser Hinsicht respektierte: hauptsächlich Österreich, Württemberg und Italien.

\begin{tabular}{|l|l|c|}
\hline & \multicolumn{1}{|c|}{ Nobilitierung } & Preußische Konfirmation \\
\hline $\begin{array}{l}\text { Adof Reinach, } \\
\text { Bankier in Frankfurt am Main }\end{array}$ & 1866 italienisches Baronat & 1867 \\
\hline $\begin{array}{l}\text { Simon Oppenheim, } \\
\text { Bankier in Köln am Rhein }\end{array}$ & 1868 österreichischer Freiherren-Stand & 1868 \\
\hline $\begin{array}{l}\text { Leopold Jacob Goldschmidt, } \\
\text { Bankier in Frankfurt am Main }\end{array}$ & $\begin{array}{l}1869 \text { württembergischer Adelstitel ad } \\
\text { personam }\end{array}$ & 1869 \\
\hline $\begin{array}{l}\text { Heinrich Herz Stiebel, } \\
\text { Bankier in Frankfurt am Main }\end{array}$ & 1869 Adelstitel in Sachsen-Meiningen & 1870 \\
\hline $\begin{array}{l}\text { Georg Daniel Weisweiller, } \\
\text { Bankier in Frankfurt am Main }\end{array}$ & $\begin{array}{l}1869 \text { württembergischer Adelstitel ad } \\
\text { personam } \\
1872 \text { spanisches Baronat }\end{array}$ & 1870 \\
\hline $\begin{array}{l}\text { Jakob Kaufmann-Asser, } \\
\text { Bankier in Köln am Rhein }\end{array}$ & 1870 österreichischer Ritterstand & 1873 \\
\hline $\begin{array}{l}\text { Adolf Liebermann, } \\
\text { Unternehmer in Berlin }\end{array}$ & $\begin{array}{l}1873 \text { österreichischer Ritterstand } \\
\text { (von Wahlendorf) }\end{array}$ & 1873 \\
\hline
\end{tabular}

Auch in den vorangegangenen Jahrzehnten hatten einige preußische Juden im Ausland ein Adelsprädikat erhalten (so stieg beispielsweise 1844 der Berliner Bankier und berühmte Hobbyastronom Wilhelm Beer in der Toskana zum Baron Colle di Val d'El$s a$ auf); dennoch erschien eine Bestätigung derartiger Titel im Mutterland lange Zeit undenkbar noch unternahmen partielle Anwärter den Versuch einer Konfirmierung. ${ }^{44}$ Zwischen ihnen und den oben aufgeführten Personen, deren ausländischen Titel man in Berlin konfirmierte, existierte allerdings ein gravierender Unterschied: Die in den Adelsstand erhobenen Personen erhielten ihr Prädikat hier mit ausdrücklicher Zustimmung des preußischen Königs.

Den Verlauf des gesamten Prozesses können wir sehr genau an drei österreichischen Nobilitierungen preußischer Juden verfolgen, zu denen es in den Jahren 1868-1873 kam. Als erster erhielt Simon Oppenheim (1803-1880) ${ }^{45}$ als älterer Bruder des in PreuBen nobilitierten Abrahams ein Adelsprädikat. Am 16. März 1867 verlieh ihm Kaiser Franz Josef I. mit Zustimmung König Wilhelms I. den Orden der eisernen Krone II. Klasse, und zwar primär aufgrund der Zusammenarbeit bei verschiedenen Finanzoperationen der Monarchie sowie für Investitionen in österreichische Staatsschuldscheine. Mit dem Orden verbunden war die Möglichkeit, um ein Baronat nachzusuchen, aller-

43 Zu dieser Frage ausführlich vgl. ebd., S. 323-330 (hier auch für die nachfolgenden).

44 Ebd., S. 203-206.

45 Österreichisches Staatsarchiv, Allgemeines Verwaltungsarchiv, Adelsarchiv (1500 ca - 1918 ca), Hofadelsakten (1600-1918), Akten (weiter nur: AVA, Adelsarchiv), Simon Oppenheim, Freiherrnstand 1868; GStA, I. HA Rep. 176 Heroldsamt, Nr. 6854 (Oppenheim 1868). 
dings lediglich im Falle österreichischer Staatsbürger. Franz Josef I. zeigt sich geneigt, eine Ausnahme zu machen, als unerlässlich erwies sich jedoch eine Zustimmung des preußischen Monarchen. Dies alles wusste Oppenheim nicht bzw. wollte dies nicht wissen, aus diesem Grunde sandte er die entsprechende Bitte um Nobilitierung am 8. Januar 1868 direkt nach Wien. Die österreichische Seite setzte Oppenheim postwendend höflich davon in Kenntnis, dass es zuvor unerlässlich sei, die Zustimmung seines Landesherrn einzuholen.

Simon sandte daraufhin offenbar umgehend die entsprechende Bitte nach Berlin, zumal bereits am 12. Januar 1868 das preußische Ministerium des Königshauses das Heroldsamt um eine Stellungnahme ersuchte. Zugleich ließ man wissen, dass man von einer möglichen Nobilitierung nicht begeistert sei. Simon allerdings erhielt bereits am 14. Februar 1868 die entsprechende königliche Zustimmung. Das ersehnte nachfolgende österreichische Diplom wurde ihm am 24. April 1868 auch wirklich erteilt. ${ }^{46}$ Bei dieser Konfirmierung mochten sowohl Simons Banken in der preußischen Wirtschaft und die Verwandtschaft zu den Rothschilds als auch der Umstand, dass seine Söhne bereits Ende der fünfziger Jahre zum Christentum konvertiert waren, eine bedeutende Rolle spielen.

Da Oppenheim eine unangenehme Ermahnung hatte hinnehmen müssen, als er um einen österreichischen Adelstitel nachsuchte, noch ehe ihm die preußische Zustimmung vorlag, wurde damit allen möglichen Antragstellern klargemacht, dass das Einverständnis Berlins einer Nobilitierung vorauszugehen sei und keineswegs umgekehrt. Lediglich in derartigen Fällen zeigte sich Preußen bereit, den Titel zu akzeptieren, zumal man damit die Situation fest unter Kontrolle hatte.

Ähnlich gestaltete sich auch die Vorgehensweise in zwei weiteren „österreichischen“ Fällen. Der erste betraf den Kölner Bankiers Jakob Kaufmann-Asser (1819-1875) ${ }^{47}$, der bereits am 7. Februar 1870 den Orden der Eisernen Krone III. Klasse erhielt. Der Grund für die Auszeichnung erwies sich als ein wenig kurios. Am 6. Februar 1870 informierte der preußische Kanzler Friedrich Ferdinand Graf Beust des österreichischen Kaiser, dass sich Jakob außerordentliche Verdienste um den Erfolg der internationalen Ausstellung in Amsterdam 1869 erworben hatte, auf der Teilnehmer aus der Monarchie zahlreiche Preise gewannen. Aus diesem Grunde verlieh ihm die niederländische Regierung das Offizierskreuz des Ordens der Eichenkrone und äußerte zugleich mit Hilfe ihres Gesandten in Wien den Wunsch, Österreich-Ungarn möge Kaufmann-Asser in ähnlicher Weise auszeichnen.

Nach der Überreichung des Ordens ersuchte Kaufmann-Asser mit Zustimmung der preußischen Regierung Kaiser Franz Josef I. um Erhebung in den Ritterstand. Nachdem der Ministerrat seine Zustimmung zur Nobilitierung erteilt hatte, schlug der

46 Es handelte sich um eine gemeinsame allerhöchste Entscheidung Wilhelms I., mit der er Simon gestattete um eine Nobilitierung nachzusuchen, und dessen Bruder Abraham den preußischen Titel eines Barons zu verleihen. Beide erhielten zudem das gleiche Wappen - der eine freilich aus Preußen, der andere aus Österreich.

47 Österreichisches Staatsarchiv, Haus-, Hof- und Staatsarchiv, Kabinettsarchiv (1523-1918), Kabinettskanzlei (1683-1918), Kabinettskanzlei Vorträge (1848-1918) (weiter nur: HHStA, KK), 490/1870; ebd., 1224/1870; AVA, Adelsarchiv, Jakob Kaufmann-Asser, Ritterstand 1870; GStA, I. HA Rep. 176 Heroldsamt, Nr. 4487. 
Innenminister Carl Giskra dem Kaiser vor, der Bitte zu entsprechen, allerdings mit dem Unterschied, der Empfänger solle im Unterschied zu österreichischen Empfängern dieses Ordens die volle Taxe bezahlen. ${ }^{48}$ Das auf diese Weise ausgestellte Memorandum unterzeichnete der Kaiser in seiner Gnade am 2. April 1870. Der Titel wurde Jakob nach Begleichung der hierfür erforderlichen Kosten per Majestätsbrief vom 15. April 1870 verliehen. Die preußische Konfirmierung erhielt er am 24. April 1871.

Der Rittertitel genügte Jakob aber keineswegs, sondern er sehnte sich nach einem weiteren durch Titel sanktionierten Aufstieg. Im nachfolgenden Jahr wandte er sich deshalb an die Gräfin Adelaida von Hacke, eine einflussreiche Palastdame der Kaiserin Augusta, mit der Bitte, diese möge ihm in Preußen zur Erreichung der Konfirmation eines von ihm angestrebten Baronats in Sachsen-Coburg-Gotha verhelfen. Als sich die Gräfin allerdings mit einer vertraulichen Anfrage an das Heroldsamt wandte, gab man ihr klar zu erkennen, dass dies ausgeschlossen sei. In diesem Zusammenhang stellt sich die Frage, was das Amt mehr störte - ein Titel des durch eine inflationäre Nobilitierungspolitik berühmt gewordenen Staates oder der Glaube des Antragstellers. ${ }^{49}$

Als letzter Jude in Preußen wurde der Textilfabrikant und Großkaufmann in Berlin, Adolf Liebermann (1829-1893), ${ }^{50}$ durch den österreichischen Kaiser nobilitiert. In seinem Falle hatte die Verleihung des Ordens der Eisernen Krone III. Klasse der k. k. Außenminister Julius Graf Andrássy initiiert. Dem Memorandum vom 27. März 1872 zufolge verteidigte Liebermanns Firma in Berlin zum einen österreichische Interessen und unterstützte die Industrie der Monarchie, zum anderen hatte sich Liebermann selbst außerordentliche Verdienste bei der Absicherung der Hilfe für verwundete und in Gefangenschaft geratene österreichische Soldaten in den Kriegen 1864 und 1866 erworben. Franz Josef billigte den Vorschlag seines Außenministers bereits zwei Tage später; wiederum drei Monate danach, am 9. Juni 1872, ersuchte Liebermann den österreichischen Monarchen um Erteilung des Rittertitels. Der Prozess der Nobilitierung zog sich allerdings in die Länge, da Liebermann diesen Schritt offenkundig nicht mit Zustimmung seines Heimatlandes unternommen hatte. Man darf vermuten, dass zunächst die österreichische Seite über dieses Thema Gespräche in Berlin führte und erst nach erfolgter Zustimmung bereitete der k. k. Innenminister Baron Lasser für Franz Josef ein umfangreiches Memorandum mit Datum 15. Februar 1873 vor. Er führte aus, dass die Nobilitierung die Unterstützung sowohl der cisleithanischen Regierung als auch des Premierministers Auersperg habe, und betonte, auch die preußische Regierung stelle sich nicht gegen eine Standeserhebung und befürworte die Verleihung des Titels. Lasser verwies zudem darauf, dass angesichts der außerordentlichen Verdienste Liebermanns eine Nobilitierung ohne entsprechende Taxe erfolge. Der Kaiser unterzeichnete am 20. Februar den entsprechenden Majestätsbrief, durch den Liebemann das Prädikat von

48 Es ging nicht allein um die Taxe für den Rittertitel, sondern Kaufmann-Asser musste, da er kein Adeliger war, auch für den übersprungenen Stand (taxa per saltum) bezahlen, was ihn zusammen 2.625 Gulden kostete. Die Taxe für den Majestätsbrief betrug 165 Gulden.

49 Drewes, K.: Jüdischer Adel, S. 329-330. Zur Frage der Nobilitierungen in Sachsen-Coburg-Gotha vgl. Andrian-Wernburg, K. von: Die Nobilitierung preußischer Untertanen.

50 HHStA, KK, 1215/1872; AVA, Adelsarchiv, Adolf Liebermann, Ritterstand (von Wahlendorf) 1873. 
Wahlendorf erhielt und der am 14. März 1873 veröffentlicht wurde. Es handelte sich dabei um ein historisches Ereignis: die letzte preußische Konfirmierung eines Adelstitels für eine Einzelperson jüdischen Glaubens.

Wenngleich die Nobilitierung von Juden in Preußen für viele Jahrzehnte ein Ende fand, bedeutete dies nicht, dass sich die Zahl der Adeligen mosaischen Glaubens im Lande nicht erhöht hätte. Hierzu kam es, wenngleich sporadisch, vor allem im Ergebnis eines Kabinettsbeschlusses vom 31. März 1872. Letzterer verfügte, dass jeder Ausländer, der die preußische Staatsbürgerschaft erhalte, ein Adelsprädikat führen dürfe, das ihm zuvor durch den Herrscher seiner ehemaligen Heimat ungeachtet der Tatsache, dass er in Preußen um eine besondere Konfirmierung nachzusuchen habe, verliehen worden sei. Im Jahre 1907 erhielt auf diese Weise der Österreicher Fritz Edler von Gutfeld (1888-1947), Sohn des 1900 nobilitierten und aus Mährisch Kromau (Moravský Krumlov) stammenden Jacob Gutfeld (1848-1911), den preußischen Adelstitel. ${ }^{51}$ In gleicher Weise nutzten ohne jegliche Schwierigkeiten in Preußen jüdische Unternehmer den Adelstitel, wobei sie ihre österreichische (oder anderwärtige) Staatsbürgerschaft beibehielten: der Kaufmann und Kunstmäzen Carl Hollitscher Edler von Hollenwarth (1845-1925), der Aufsichtsrat der Berliner Nationalbank für Deutschland Julius Edler von Peter (1855-1934) und der Bankier Ludwig von Berl (1856-1923). ${ }^{52}$

$$
* * *
$$

Seit der Mitte der siebziger Jahre des 19. Jahrhunderts erfolgte in Preußen nicht mehr nur keine Nobilitierung von Juden mehr, auch Einzelpersonen jüdischer Herkunft wurden nur in Ausnahmefällen in den Adelsstand erhoben. Aus den Reihen aktiver Offiziere erhielt niemand ein Adelsprädikat, auch unter den Staatsbeamten gab es nur sehr wenige Nobilitierungen. Einer der in den Adelsstand Erhobenen war der berühmte Verfassungsrechtler, wirkliche Geheimrat und Präsident des Reichsgerichts Martin Eduard Simson (1810-1899). Getauft wurde er zusammen mit seiner Familie im Jahre 1823, 1888 erhielt er auf der Grundlage des Schwarzen Adler-Ordens, dem ihm Friedrich III. verlieh, den Adelstitel. ${ }^{53}$

Auch unter den nobilitierten Unternehmern finden wir kaum Personen mit jüdischem Blut. Der Hass gegen deren Herkunft überdauerte ganze Generationen, wie auch aus dem oben erwähnten Fall der Familie Mendelssohn und Mendelssohn-Bartholdy hervorgeht, deren Angehörige in den Jahren 1888, 1896 und 1907 ein Adelsprädikat

51 HHStA, KK, 1313/1900, AVA, Adelsarchiv, Jacob Gutfeld, Adelstand (Edler von) 1900; GStA, I HA Rep. 176 Heroldsamt, Nr. 3060 (Edler von Gutfeld).

52 Mit deren Adelsstand beschäftigten sich die preußischen Behörden überhaupt nicht. Eine Ausnahme stellte lediglich die Familie von Peter dar, bei der sich das Berliner Polizeipräsidium nicht sicher war, auf welcher Grundlage diese den Titel trage (es existierte nämlich eine im Jahre 1790 vom bayerischen Kurfürsten als Reichsvikare nobilitierte Familie von Rittern und Adeligen gleichen Namens). Vgl. GStA, I. HA Rep. 176, Nr. 7539. 
erhielten. ${ }^{54}$ Mit Ausnahme des Barons Delmar wurden in Preußen in den Jahren 18591912 lediglich elf jüdische Konvertiten in den Adelsstand erhoben. Zur Zeit der Nobilitierung waren alle Protestanten. Sämtliche Nobilitierte erhielten zudem lediglich einen einfachen Adelstitel. ${ }^{55}$

\begin{tabular}{|l|l|c|}
\hline Datum & Name und Beruf & Datum der Konvertierung \\
\hline 1859 & $\begin{array}{l}\text { Georg Moritz Oppenfeld (1793-1861), ehemals Moses } \\
\text { Oppenheim, Bankier in Berlin und Großgrundbesitzer }\end{array}$ & 1822 \\
\cline { 2 - 4 } & $\begin{array}{l}\text { Carl Daniel Oppenfeld (1800-1861), ehemals Daniel } \\
\text { Oppenheim, Bankier in Berlin und Großgrundbesitzer }\end{array}$ & 1822 \\
\hline 1861 & Siegfried Normann (1802-1874), Bankier in Berlin & 1861 \\
\hline 1863 & $\begin{array}{l}\text { Wilhelm Ludwig Uckro (1793-1874), ehemals Schlesin- } \\
\text { ger, Großgutbesitzer }\end{array}$ & 1814 \\
\hline 1906 & Georg Caro (1849-1913), Großindustrieller & vor 1906 \\
\hline 1906 & $\begin{array}{l}\text { Fritz Friedlaender (1858-1917), Großindustrieller in } \\
\text { Berlin und Großgrundbesitzer (nach der Nobilitierung } \\
\text { von Friedlaender-Fuld) }\end{array}$ & 1898 \\
\hline 1907 & $\begin{array}{l}\text { Paul Schwabach (1867-1938), Bankier in Berlin } \\
\text { Arthur Weinberg (1860-1943), Großindustrieller in } \\
\text { Frankfurt am Main }\end{array}$ & 1880 \\
\hline 1908 & $\begin{array}{l}\text { Carl Weinberg (1861-1943), Großindustrieller in Frank- } \\
\text { furt am Main (Bruder von Arthur Weinberg) }\end{array}$ & 1880 \\
\hline 1908 & $\begin{array}{l}\text { Eduard Beit (1860-1933), Bankier in Frankfurt am Main } \\
\text { (nach der Nobilitierung Beyt von Speyer) }\end{array}$ & 1860 \\
\hline 1910 & $\begin{array}{l}\text { Friedrich Gans (1833-1920), Großindustrieller in Frank- } \\
\text { furt am Main }\end{array}$ & 1895 \\
\hline 1912 & \multicolumn{2}{|c|}{} \\
\hline
\end{tabular}

Die Regierung des liberalen Friedrich III., die nicht an antisemitischen Vorurteilen litt, verkörperte lediglich eine kurze Episode, unter Wilhelm II. setzte die preußische Nobilitierungspolitik in der verfolgten Linie fort. Der Monarch realisierte seine Bemühungen, die auf eine Reform der konservativen preußischen Elite hinausliefen, angesichts der eigenen Konzeptionslosigkeit und des Nichtvorhandenseins eines wohldurchdachten Plans diese Idee letztlich. Ebenso wie sein Großvater befand er sich darüber hinaus in der Frage der Erteilung von Adelstiteln in ständigem Konflikt zu den Vorstellungen des

54 Franz von Mendelssohn (1829-1889) im Jahre 1888 - GStA, I. HA Rep. 176 Heroldsamt, Nr. 6100 (Mendelssohn), Ernst Mendelssohn-Bartholdy (1846-1909) 1896 - ebd., Nr. 6168 (Mendelssohn-Bartholdy 1896) und Otto (1868-1949) im Jahre 1907 - ebd., Nr. 6378 (Mendelssohn-Bartholdy 1907). Otto erhielt angeblich sein Adelsprädikat als Geschenk für die Villa Falconieri Wilhelms II. in Frascati bei Rom. Vgl. Hertzt-Eichenrode, D.: Wilhelminischer Neuadel?, S. 660 (der Autor verwechselt Otto mit Ernst, der bereits früher nobilitiert worden war). In den Materialien des Heroldsamts finden sich keinerlei Hinweise über diese Transaktion.

55 Die Tabelle ist übernommen aus Drewes, K.: Jüdischer Adel, S. 394. Sie wurde um Geburts- und Sterbedaten ergänzt, korrigiert wurde darüber hinaus das Datum der Konvertierung bei Eduard Beit - vgl. GStA, I. HA Rep. 176 Heroldsamt, Nr. 1149 (Beit von Speyer 1910). Es hat den Anschein, dass alle Lutheraner waren. Eine Ausnahme bildete Georg Caro, der sich zur evangelisch-unierten Confession bekannte. Ebd., Nr. 1621 (Caro). 
konservativen Heroldsamts. Der König teilte zwar die antisemitischen Ansichten seiner Beamten nicht, auf der anderen Seite vermochte er deren antijüdische Ausfälle nicht abzuschwächen. Wenngleich er im Vergleich zur vorangegangenen Ära die Zahl der Adeligen jüdischer Herkunft zu erhöhen vermochte (unter der Regierung Wilhelms II. erhielten 20 Personen ein Adelsprädikat), blieb deren Anteil innerhalb der preußischen Elite marginal. ${ }^{56}$

Dennoch kam es in der zweiten Dekade seiner Regierung zu einer gravierenden Wende: nach 30 Jahren wurden wiederum ein praktizierender Jude in den Adelsstand erhoben und kurz darauf mehreren Konvertiten ein Adelsprädikat verliehen. Bei diesem einzigen, in den Adelsstand erhobenen Bürger mosaischen Glaubens handelte es sich um den Bankier und österreichisch-ungarischen Generalkonsul in Frankfurt am Main Maximilian Benedikt Hayum Goldschmidt (1843-1940). Seinen Adelstitel erhielt er aller Wahrscheinlichkeit nach aufgrund der Tatsache, dass er dank seiner Heirat mit Minna Caroline von Rothschild (1857-1903) zum Erben der ausgestorbenen Frankfurter Linie der Rothschilds aufstieg. ${ }^{57}$

Alles steht nicht ganz fest, ob er sich ursprünglich um diesen Titel bemüht hatte. ${ }^{58}$ Es hat den Anschein, als ob er sich sehr wohl der Kompliziertheit von Nobilitierungen von Juden im Königreich Preußen bewusst war und deshalb am 19. Dezember 1901, nicht einmal ein Jahr nach dem Tode seines Onkels, des Barons Wilhelm Karl von Rothschild (1828-1901), der am 25. Januar 1901 verstorben war, bei den preußischen Behörden lediglich um eine Verbindung seines und des Namens seiner Frau zu Goldschmidt von Rothschild nachsuchte. Diese Möglichkeit bestand grundsätzlich, zumal der Zusatz von preußischen Gewohnheiten zufolge nicht automatisch eine Zugehörigkeit zum Adels bedeutete. Während der Regierungspräsident in Wiesbaden die Bitte am 16. August 1902 zu erfüllen empfahl, lehnte das Heroldsamt diese postwendend bereits am 20. Februar 1902 mit der Begründung ab, dies sei lediglich dergestalt möglich, künftig den Doppelnamen Goldschmidt-Rothschild zu führen. Nach reiflicher Überlegung bat Maximilian daraufhin am 13. Oktober 1902 lieber gleich um die Verleihung eines Adelstitels.

Das Heroldsamt sprach sich wie üblich gegen das Memorandum vom 22. November 1902 aus. Auch wenn es anerkannte, dass für die Verleihung des Titels Reichtum und Wohltätigkeit beider außerordentliches Gewicht hätten - Maximilian war der viertreichste preußische Bürger mit einem Vermögen, das mehr als 100 Millionen Mark ausmachte ${ }^{59}$ - überwog das Negativum in Gestalt des jüdischen Bekenntnisses. Wilhelm II. stellte sich jedoch im konkreten Fall gegen seine Beamten. Mit Majestätsbrief vom 6. September

56 Es handelte sich nicht allein um die Konvertiten selbst, die in der Tabelle oben aufgeführt sind, sondern zugleich um die Nachfahren der Konvertierten. D. Hertz-Eichenrode (Herzt-Eichenrode, D.: Wilhelminischer Neuadel?, S. 654) verweist bei dieser Zahl auf Lamar, C.: The Creation of Nobles in Prussia, S. 768). Letzterer erwähnt allerdings für die Regierungszeit Wilhelms II. lediglich sieben nobilitierte Personen jüdischen Glaubens bzw. Herkunft. D. Hertz-Eichenrode irrt zudem, wenn er Friedrich Gans (nobilitiert 1912) als Person jüdischen Glaubens anführt. Gans war bereits im Jahre 1885 konvertiert und mit seinen Kindern zum Luthertum übergetreten. Zu seinem Fall weiter unten.

57 Letztens Mitglied dieses Zweiges war Minnas Vater Wilhelm Karl Freiherr von Rothschild (1828-1901).

58 Vgl. GStA, I. HA Rep. 176 Heroldsamt, Nr. 2993 (Goldschmidt-Rothschild).

59 Drewes, K.: Jüdischer Adel, S. 115. 
1903 ließ er das Ministerium des Königshauses und das Heroldsamt wissen, er werde Goldschmidt in den Adelsstand erheben und ihm das Prädikat „von Goldschmidt-Rothschild“ - und zwar auf der Grundlage seines gegenüber dem Geheimen Kabinettsrat und Präsidenten der Provinz Hessen-Nassau geleisteten Eids, in Preußen einen Fideikommiss im Werte von mindestens zwei Millionen Mark zu gründen. ${ }^{60}$

Aller Wahrscheinlichkeit nach hatte Maximilian bereits zu dieser Zeit mit dem König vereinbart, auch den - die Primogenitur berücksichtigenden - erblichen Titel eines Freiherrn zu erhalten. Bereits am Tage der Nobilitierung hinterlegte er eine Garantie über 5.250 Mark mit dem Zusatz, die restliche Summe in Höhe von 13.650 Mark sei umgehend zu zahlen vorbereitet. Es handelte sich um die mit den Taxen verbundene Gesamtsumme für die Verbindung von Namen, einfachem Adelstitel und Baronat. ${ }^{61}$ Aus der sich anschließenden Entwicklung geht hervor, dass Wilhelm II. Maximilian in den Adelsstand aufgrund der Tatsache erhob, dass der Bankier das Baronat in dem Augenblick erhalten sollte, in dem er das Fideikommiss gründete. Eine solche Vorgehensweise fand in Preußen relativ häufig Anwendung.

Bereits am 29. Januar 1904 informierte Goldschmidt-Rothschild aus Frankfurt am Main Berlin, er habe das Fideikommiss Wroniawy in der Provinz Posen begründet, doch dauerte es noch mehr als ein Jahr, ehe dessen Existenz am 23. Dezember 1905 durch das Oberlandesgericht Posen gebilligt wurde, und ein weiteres Jahr verging, ehe am 24. November 1906 der Monarch das Dokument konfirmierte. Grundlage des in männlicher wie weiblicher Primogenitur vererbbaren Fideikommiss bildete das Rittergut Wroniawy im Bezirk Bomst (heute Babimost), das mehr als 2.146 Hektar umfasste.

Erst jetzt erhielt Maximilian die Bestätigung seines Adelstitels - und zwar gleich in doppelter Form. Am 26. März 1907 wurde ihm das die Erteilung eines einfachen Adelstitels bestätigende Diplom verliehen, das auf den 6. September 1903 datiert war, kurze Zeit später - am 22. April 1907 - folgte der Majestätsbrief, der die Erhebung in den Stand der Freiherren beinhaltete, erblich für den erstgeborenen Sohn und Erben des Familienmajorats. ${ }^{62}$

Eine interessante Situation trat drei Jahre später ein, als Wilhelm II. aus rein höfischen Gründen das Baronat ad personam dem ältesten Sohn Maximilians und dem Erben des Titels Albert (1879-1941) verlieh. Dieser war nämlich mit seiner Cousine Miriam de Rothschild (1884-1965) verlobt, deren Vater aus der Pariser Linie der Familie stammte, wobei Albert den Wunsch hegte, seine Frau möge nach der Heirat weiterhin das Baronat nutzen. ${ }^{63}$ Für den Titel, den freilich nur ihm persönlich der König am

60 Das Schreiben Wilhelms II. vom 6. 9. 1903. In: GStA, I HA Rep. 176 Heroldsamt, Nr. 2993 (Goldschmidt-Rothschild). Hier auch die übrigen Informationen zur Nobilitierung.

61 Die Summe für den einfachen Adelstitel betrug 3.600 Mark (plus 600 Mark für die Stempelmarke), die Verbindung der Namen kostete 900 (plus 150) Mark und der Freiherrenstand schließlich 7.200 (und 1.200) Mark. Ebd.

62 Zur Familie vgl. u. a. Županič, J.: Židovská šlechta [Der jüdische Adel], S. 267-270.

63 In die Bitte an Wilhelm II. vom 25. 11. 1911 fügte Albert dezidiert ein: „Wenn auch meine Braut sehr einfach und bescheiden ist, so habe ich doch den großen Wunsch, daß sie auch als meine Frau dem freiherrlichen Stande weiter angehören möge.“ Zitiert nach: GStA, I. HA Rep. 176 Heroldsamt, Nr. 2993 (Goldschmidt-Rothschild). 
19. Januar 1911 erteilte, musste Albert die volle Taxe der Standeserhebung in Höhe von 9.600 Mark zahlen.

$$
* * *
$$

Wie bereits wiederholt angesprochen, verliefen nicht einmal Nobilitierungen von Personen, die vom jüdischen Glauben zum Christentum konvertiert waren, problemlos. Dies geschah insbesondere in Fällen, in denen es sich um Unternehmer handelte, die für ihren Titel großzügige finanzielle Geschenke machten. Ein Großteil der traditionellen Elite Preußens sah derartige Verdienste als nicht ausreichend an und auch die Presse kritisierte wiederholt solche Schritte. Doch gerade auf der Grundlage ihres großzügigen Mäzenatentums erhielten fünfzig Jahre nach der Nobilitierung des letzten Konvertiten am 27. Februar 1906 gleich zwei ehemalige Juden ein Adelsprädikat - die Berliner Unternehmer Fritz Friedlaender und Georg Caro.

Friedlaender, Sohn des Besitzers einer Kohlengroßhandlung im oberschlesischen Gleiwitz (Gliwice) Emanuel (1824-1880), war Eigentümer großer Braunkohlegruben in der oberschlesischen Region und einer der Hauptproduzenten von Koks und Briketts. Mit seinem Besitz in Höhe von annähernd 46 Millionen Mark zählte er zu den reichsten Männern Deutschlands. Ihm gehörten zahlreiche Immobilien und in Berlin bewohnte er ein luxuriöses Haus am Pariser Platz in Nachbarschaft zum Brandenburger Tor. Die Nobilitierung war in seinem Falle das Ergebnis einer internen Abmachung mit dem Monarchen. ${ }^{64}$ Der schlesische Kohlenbaron hatte nämlich eine Million Mark in die verfallenden Danziger Eisenwerke investiert und versprochen, aus seiner Herrschaft Loslau ein Familienfideikommiss zu machen. Beide Ankündigungen erfüllte er auch, wenngleich die Errichtung des Familienfideikommisses einige Jahre dauerte. Trotz der außerordentlichen Summe, die ihn die Standeserhebung kostete, musste er auch die weiteren - mit der Nobilitierung verbundenen - Taxen begleichen, was jedoch bei ähnlich vermögenden Personen üblich war. ${ }^{65}$ Die Taxe bezahlte Friedlaender umgehend, aufgrund der Verzögerung bei der Einrichtung des Fideikommisses zog sich allerdings die Ausstellung des Majestätsbriefes einige Jahre dahin.

Friedlaender war nämlich Besitzer gleich mehrerer Großgüter, u. a. der Herrschaft Lanke mit einem prachtvollen Schloss unweit von Berlin, der kleineren Standesherrschaft Loslau (heute Wodzistaw Ślaski) ${ }^{66}$ sowie des unweit hiervon gelegenen Rittergutes

64 Wilhelm II. ließ den Minister des Königshauses und das Heroldsamt wissen, er habe Friedlaender in den Adelsstand erhoben „nachdem derselbe sich bereit erklärt hat, die ihm gehörige Minderstandesherrschaft Loslau im Kreise Rybnik zum Familienfideikomiß zu stiften. Der Anfertigung und Vorlegung des Diploms sehe ich entgegen, nachdem die Stiftungsurkunde genehmigt ist." Zitiert nach: GStA, I. HA Rep. 176 Heroldsamt, Nr. 2593 (Friedlaender-Fuld).

65 Für diesen Titel bezahlte Friedlaender 4.500 Mark, 750 Mark betrug die Stempelsteuer, hinzu kamen 515,50 Mark für die Ausfertigung des Diploms.

66 Als Standesherrschaften wurden in Schlesien Komplexe von Gütern bezeichnet, die nicht lokalen Fürsten unterstanden, sondern unmittelbar dem König. Während jedoch die Besitzer freier Standesherrschaften das Recht besaßen, am Landtag teilzunehmen, stand den Besitzern kleinerer Herrschaften (Minderstandesherrschaften) ein solches Privileg nicht zu. Im 19. Jahrhundert handelte es sich lediglich um eine Ehrenbezeichnung ohne praktische Bedeutung. 
Groß Gorschütz (Gorzyce), beide in Oberschlesien. Mit Blick auf die Interessen des preuBischen Staates entschied sich Friedlaender schließlich für den Besitz in Schlesien. Die beiden dort gelegenen Herrschaften waren nämlich mehrheitlich von Polen besiedelt. Ursprünglich sollte aus Loslau ein Fideikommiss gebildet werden, Friedlaender ändert jedoch am Ende seine Pläne und entschied sich für das kleinere Gut Groß Gorschütz mit einem Umfang von 656 Hektar und einem Jahresertrag von 11.908 Mark. Den Grund hierfür gab er nicht an, doch könnte dieser darin zu suchen sein, dass dieses näher am deutschen Sprachgebiet lag und sich dadurch günstiger für eine deutsche Kolonisierung eignete. Das Heroldsamt wandte zwar ein, dass es sich mit Blick auf Friedlaenders Eigentum um einen unbedeutenden Besitz handele, Fritz bat jedoch am 20. November 1908 den Monarchen um eine Akzeptanz dieser Änderung und die Zustimmung für ein - in männlicher wie weiblicher Primogenitur vererbbares - Fideikommiss. ${ }^{67}$ Wilhelm II. segnete Friedlaenders Bitte am 27. Juni 1909 an Bord seiner Jacht Hohenzollern ab und erst jetzt begannen die Arbeiten an der Ausfertigung der Nobilitierungsurkunde.

Das Diplom wurde Friedlaender mit Datum 7. Februar 1910 erteilt, wobei man expressis verbis betonte, es sei bereits am 27. Februar 1906 zur Standeserhebung gekommen. Zugleich erhielt Friedlaender durch den Majestätsbrief den neuen Namen Friedlaender-Fuld. Fritz hatte nämlich um eine Verknüpfung seines Familienamens mit jenem seiner Frau gebeten, der in Amsterdam geborenen Milly Antonie Fuld (1866-1943), die aus einer alteingesessenen jüdischen Familie aus Frankfurt am Main stammte. Auch für Georg Caro sollte der Adelstitel richtig viel Geld kosten, wenngleich die Summe nicht jene erreichte, die Friedlaender zahlen musste. Angeblich sollte er seine Nobilitierung dafür erhalten, dass er für 300.000 Mark ein Erholungsheim für die kaiserliche Flotte erbaute. ${ }^{6}$ Auch Caro stammte aus Schlesien, aus einer alten und bekannten, in Breslau ansässigen Sephardenfamilie. Unter seinen direkten Vorfahren finden wir auch den Vater des berühmten Prager Rabbi Jehuda ben Becalel (zwischen 1512 und 1525-1609). Im 19. Jahrhundert spielten Familienmitglieder eine wichtige Rolle in der Wirtschaft des preußischen Staates und Georgs Vater Robert (1819-1975), ein Großkaufmann und Hüttenbesitzer in Schlesien, wurde für seine Verdienste zum preußischen Kommerzienrat ernannt. Georg selbst gehörte zu den bedeutendsten Persönlichkeiten der schlesischen Industrie und reichsten Bewohnern Preußens. Er investierte auch in Immobilien und zu Beginn des 20. Jahrhunderts erwarb er die brandenburgischen Herrschaften Wilkendorf und Gielsdorf mit einer Gesamtfläche von 2.600 Hektar.

Seine Nobilitierung verlief nach dem gleichen Szenarium wie bei Friedlaender. ${ }^{69}$ Am 27. Februar 1906 teilte Wilhelm II. dem Minister des Königshauses Wilhelm von Wedel sowie dem Heroldsamt mit, er habe Caro auf dessen Bitte hin in den Adelsstand erhoben „nachdem derselbe sich bereit erklärt hat, die ihm gehörige Güter Wilkendorf und Gielsdorf bei Strausberg zum Familienfideikomiß zu stiften. Der Anfertigung und Vorlegung des Diploms sehe ich entgegen, nachdem die Stiftungsurkunde genehmigt

67 Friedlaenders einziges Kind war die Tochter Marie Anna (1892-1973).

68 Herzt-Eichenrode, D.: Wilhelminischer Neuadel?, S. 660-662. In Caros Schreiben an das Heroldsamt findet sich diese Information nicht. 
ist“. Es handelte sich um die vollständig identische Formulierung, wie wir sie auch bei Friedlaender finden, und auch der weitere Ablauf war der gleich. Auch Caros Nobilitierung zog sich in die Länge, allerdings lag die Schuld hier in der gründlichen Prüfung der Urkunde beim zuständigen Bezirksgericht. Erst am 25. November 1908 konnte er dem Heroldsamt das Dokument zur Einrichtung eines - in männlicher wie weiblicher Linie erblichen - Fideikommisses zusenden. Das Dokument war sehr präzise ausgearbeitet, außer der nachfolge waren hier auch die genauen Summen aufgelistet, die dem Besitzer des Fideikommisses und weiteren Familienmitgliedern auferlegt waren. Nachfolgend wurde am 29. März 1909 das Adelsdiplom ausgestellt, indem wiederum ausdrücklich das Datum der Standeserhebung Februar 1906 aufgeführt wurde. ${ }^{70}$

Weder die genaue Bedingung der Nobilitierung, wie sie die Einrichtung eines Fideikommiss darstellte, noch die gesellschaftliche Stellung beider Neuadeligen genügten freilich in den Augen eines Teils der Gesellschaft, um den Makel der jüdischen Herkunft zu beseitigen. Nach mehr als fünf Dekaden „reinrassiger“ Nobilitierungen tauchten unter den preußischen Adeligen wiederum neue Personen auf: zuerst der Jude Goldschmidt-Rothschild und nach ihm zwei Konvertiten, die erst als Erwachsene ihr Judentum ablegten.

Es war offenkundig kein Zufall, dass der gut informierte Journalist Maximilian Harden (1861-1927), der bald darauf Initiator eines der größten Skandale im deutschen Kaiserreich - der sog. Harden-Eulenburg-Affäre (1907-1909) ${ }^{71}$ - werden sollte, kurz vor der offiziellen Bekanntgabe der Nobilitierung Friedlaenders und Caros am 10. März 1906 in seiner einflussreichen Wochenzeitschrift Die Zukunft einen ironischen Artikel unter dem Titel Die neuen Ritter veröffentlichte. Harden lieferte keine konkreten Details, sondern konstatierte lediglich, er sei empört über die neuesten Entscheidungen hinsichtlich der Erteilung von Adelstiteln und Orden. Er verkündete, es sei allgemein bekannt, dass der Staat diese Ehren bereits ab 50.000 Mark verkaufe und dass er auf diese Weise das im erschöpften preußischen und gesamtdeutschen Haushalt fehlende Gelder für öffentliche Zwecke kompensiere. Der Artikel besaß keine antisemitische Stoßrichtung, sondern attackierte eher die Schritte Wilhelms II., die Harden zufolge das Prestige der Monarchie gefährdeten und zu einer offenen Kritik der Handlungen des Monarchen im Parlament führten. ${ }^{72}$ In der Berliner Gesellschaft hatte man jedoch bereits über Friedlaenders und Caros Nobilitierung als von einer unverdeckten Korruption gesprochen, wobei man annahm, der Titel müsse beide Männer annähernd eine Million Mark gekostet haben. ${ }^{73}$

70 Am 28. 9. 1910 wurde zudem auf Georgs Bitte hin seine Adoptivtochter (und einziges Kind) Adele Caro-May (1899-1974) nobilitiert, die diesen Namen auf der Grundlage des Vormundschaftsvertrages vom 19. 04. 1906 trug. Sie war die Tochter von Georgs erster Gemahlin Julie Mathilde May, geborene Esser (1856-1900) und Joseph Arthur Mays (1867-1899). Nach der Nobilitierung benutzte Adele auf Wunsch ihres Vaters und mit Zustimmung des Monarchen nur den Namen von Caro.

71 Im Verlaufe der Affäre wurde u. a. der enge Freund Kaiser Wilhelms II. und Kopf der Hofkamarilla, Fürst Philipp von Eulenburg (1847-1921), der Homosexualität bezichtigt wurde. Vgl. Winzen, Peter: Das Kaiserreich am Abgrund. Die Daily-Telegraph-Affäre und das Hale-Interview von 1908. Darstellung und Dokumentation, Stuttgart 2002. s. 323.

72 Die neuen Ritter, in: Die Zukunft, Jg. XIV, Bd. 54, 10. 3. 1906, S. 357-359.

73 Hertz-Eichenrode, D.: Wilhelminischer Neuadel?, S. 660-661. 
Das preußische Heroldsamt verzeichnete die Ansichten der Presse sehr genau. ${ }^{74}$ In Friedlaenders Schrift wird so der scharfe antisemitische Artikel aus der Zeitschrift Wahrheit vom August 1908 ausgelegt. Der Autor führt aus, Friedlaender sei elf Jahre zuvor nach Berlin übergesiedelt und zum Christentum übergetreten. An seiner wahren religiösen Überzeugung wurden jedoch postwendend Zweifel geäußert, zumal, wie der Artikel betont, er bereits seit neun Jahren keine Kirchensteuer mehr zahle. Als man Friedlaender auf diesen Umstand aufmerksam gemacht habe, hätte er angeblich mit den Worten reagiert, die Sache sei bereits verjährt. Als größtes Problem erachtete der Autor jedoch, dass Fritz dem Kaiser für seine Nobilitierung versprochen habe, das Defizit der Danziger Eisenwerke zu decken, was er freilich nicht getan habe, da sich letztere jetzt in Konkurs befänden.

In der Schrift ist darüber hinaus ein weiterer, ganz anders ausgerichteter Artikel unter dem Titel Die neusten Berliner Adeligen enthalten, der Friedlaender und Caro demgegenüber lobte. Der Verfasser bezeichnete die Nobilitierungen als zu erwartende Standeserhebung, zumal beide Personen zu den sehr Vermögenden gehörten. Er verkündete, dass er die deutsche (und hauptsächlich preußische) nationale Politik unterstütze und durch den Kauf polnischer Güter die deutsche Präsenz im Osten verstärke, wodurch er sich grundsätzlich von vielen preußischen Adeligen unterscheide, die ihren Besitz an Polen verkaufen würden. Der Verfasser hob besonders Friedlaender hervor, der einer der größten Steuerzahler in Berlin sei, darüber hinaus ein bedeutender lokaler Mäzen, der auf eigene Kosten Häuser am Pariser Platz erworben und abreißen habe lassen, um die Dominanz des Brandenburger Tores besser zur Geltung zu bringen. ${ }^{75}$

$$
* * *
$$

Nicht alle Nobilitierungen jüdischer Konvertiten waren mit der Verpflichtung zur Einrichtung eines Fideikommisses verbunden. Die Bankiers Paul Schwabach und Eduard Beit wurden in den Adelsstand ohne weitere Verpflichtungen erhoben, wobei dieser Schritt in der Presse auch keinerlei Aufsehen erregte. Der Berliner Finanzier Paul Hermann Schwabach ${ }^{76}$ - studierter und sogar promovierter Historiker - übte neben seiner eigentlichen Profession seit 1898 auch das prestigeträchtige Amt des britischen Generalkonsuls aus. Er war Mitinhaber der einflussreichen Bank S. Bleichröder, in der er seit 1896 arbeitete und zwei Jahre später zum Direktor aufstieg. Im Juni 1903 verlieh ihm der preußische König den Schwarzen Adler-Orden IV. Klasse und im Januar 1904 denselben Orden III. Klasse. In Schwabachs Fall hatte Wilhelm II. die Nobilitierung selbst initiiert,

74 Die Verleihung des Adels an v. Friedländer-Fould und der Konkurs der Danziger Industriewerke, in: Wahrheit, 22. 8. 1908; Die neuesten Berliner Adeligen, sine dato et loco. Alles in: GStA, I. HA Rep. 176 Heroldsamt, Nr. 2593 (Friedlaender-Fuld). Auch für den nachfolgenden Fall.

75 Die neuesten Berliner Adeligen. Das Schreiben, in dem der Artikel abgedruckt ist, wird in der Schrift nicht erwähnt. Auch dieser Artikel enthält jedoch Fehler. Der Autor glaubte beispielsweise, dass Friedlaender Katholik sei. Auch konnte er nicht die Information verifizieren, Friedlaender habe bereits im Ausland einen Adelstitel erworben. 
dessen Geheimes Zivilkabinett am 7. März 1907 das Heroldsamt um die Zusendung vertrauenswürdiger Informationen über die soziale Stellung und das politische Denken des Bankiers bat.

Die entsprechende Expertise erstellte für die Behörde am 5. April 1907 das Berliner Polizeipräsidium, das bei Schwabach keinerlei Verfehlungen konstatierte und seine moralischen und politischen Handlungen als makellos beschrieb. Zugleich lieferte sie dem Heroldsamt interessante Informationen über Schwabachs ökonomisches Umfeld. Der Bankier lebte damals in einer luxuriösen Wohnung im Zentrum Berlins in der Mauerstraße 35-36. Im ersten und zweiten Geschoss des Hauses gehörte ihm eine Wohnung mit annähernd 30 Zimmern, für die er die enorme Summe von 30.000 Mark Miete im Jahr bezahlte. Seine jährlichen Bezüge für den Direktorenposten schätzte man auf 1,6 bis 1,7 Millionen Mark, das Gesamtvermögen auf ungefähr 8,4 Millionen Mark. Das Heroldsamt kommentierte die Angelegenheit nicht weiter und übergab die Unterlagen dem Monarchen. Auf deren Grundlage erteilte Wilhelm II. der Nobilitierung am 22. April 1907 seine endgültige Zustimmung, so dass Schwabach das Adelsdiplom am 16. Juni 1907 erhielt.

Ein wenig abweichend hiervon verlief zwei Jahre später die Nobilitierung Eduard Beits. ${ }^{77}$ Im Unterschied zu den übrigen hier erwähnten Männern, die als Erwachsene konvertierten, wurde Beit in der Hamburger Hauptkirche St. Petri bereits sechs Wochen nach seiner Geburt lutherisch getauft. Bei den Beits handelte es sich um eine alte jüdische Familie portugiesisch-holländischer Herkunft, die sich um 1600 in Deutschland niedergelassen hatten, und seit dem Beginn des 18. Jahrhunderts wirkten deren Angehörige in Hamburg, wo sie sich mit dem Handel von Edelmetallen beschäftigten. Eduards Leben war mit Frankfurt am Main verbunden, wohin er in eine andere bedeutende jüdische Familie - die Speyers - einheiratete. Die Speyers hatten im verlaufe des 19. Jahrhunderts in London, New York und Frankfurt drei Bankhäuser gegründet, wobei gerade Beit mit der Führung des Frankfurter Geldinstituts im Jahre 1902, zweifellos im Ergebnis der Heirat mit Hanna Lucie Speyer (1870-1918) 1892, betraut wurde. 1910 gehörte Beit zu den acht reichsten Männern Preußens mit einem Vermögen von 76 Millionen Mark. ${ }^{78}$ Im November 1905 erhielt Eduard den prestigeträchtigen Titel eines preußischen Kommerzienrates und am 19. Dezember 1909 bat er Wilhelm II. um die Verleihung eines Adelstitels und die Genehmigung der Namensführung Beit von Speyer. Da das Heroldsamt hiergegen keine Einwände erhob, wurde Eduard nach Bezahlung der fälligen Taxen am 23. März 1910 nobilitiert.

Während die Erhebung Schwabachs und Beits ohne größere Aufmerksamkeit der Presse und der Öffentlichkeit erfolgte, rief in Preußen die letzte ,jüdische“ Nobilitierung,

77 Ebd., Nr. 1149 (Beit von Speyer 1910).

78 Drewes, K.: Jüdischer Adel, S. 115. 
diejenige des Großindustriellen Friedrich Ludwig Gans großes Aufsehen hervor. ${ }^{79}$ Auch Gans stammte aus einer alteingesessenen und sehr reichen jüdischen Familie, doch konvertierte er um 1895 mit seinen Kindern zum Luthertum. Er war Mitbesitzer einer der größten chemischen Fabriken in Deutschland, Kunstkenner und -liebhaber sowie großzügiger Mäzen, wenngleich sein Vermögen im Vergleich zu Goldschmidt-Rothschild oder Beit von Speyer wesentlich geringer ausfiel. ${ }^{80}$

Die Nobilitierung war das Ergebnis eines spezifischen Vertrages mit dem preußischen König, in deren Rahmen Gans seine außerordentlich wertvolle und einmalige Sammlung antiker Gegenstände dem Königlichen Museum in Berlin schenkte und Wilhelm II. Gans als Entlohnung dafür am 4. November 1912 in den Adelsstand erhob.

Friedrich Ludwig bemüht sich freilich nicht allein um einen Adelstitel. In einem Schreiben vom 4. Dezember 1911 bat er Wilhelm II. offiziell um den in Primogenitur wirksamen erblichen Titel eines Freiherren - verbunden mit der Herrschaft Niesen bei Warburg in der Provinz Hessen-Nassau. Aus diesem Rittergut mit einer Fläche von 1061 Hektar, das Gans am 11. November 1911 für die Summe von zwei Millionen Mark von dem damals erst 24-jährigen Hermann Graf von Bocholtz erwarb, beabsichtigte er ein Fideikommiss zu bilden. Wie sich jedoch bald darauf zeigte, traten beim Erwerb des Gutes Probleme auf, weil es den Informationen des preußischen Justizministeriums vom 15. März 1912 zufolge es nicht auf der Grundlage der Verpflichtungen in den Grundbüchern außerhalb der Familie von Bocholtz verkauft werden durfte. Gans schlug aus diesem Grunde bereits am 29. Januar 1912 die Einrichtung eines Geld-Fideikommiss vor, sein Vorschlag wurde jedoch, wie aus den Dokumenten hervorgeht, offenbar nicht in Betracht gezogen. Daher verzichtete er schließlich auf das Baronat und am 2. April 1912 bezahlte er die mit der Erteilung des Adelstitels verbundenen Taxen.

Wenngleich Gans also den Titel eines Barons nicht erhielt, rief seine Erhebung in den Adelsstand selbst außerordentliche Aufmerksamkeit hervor. Noch vor der Nobilitierung attackierte der Oberpräsident der Provinz Westfalen Dr. Georg von Borries, der in einer Nachricht an das Heroldsamt vom 21. Januar 1912 Gans' Verdienste als für die Verleihung eines Adelsprädikats ungenügend bezeichnete. Er ließ verlautbaren, dass es großzügig und edel sei, wenn Gans seine Sammlung dem Museum ohne Anspruch auf Entlohnung übereigne oder diese Einrichtung testamentarisch bedenke. Zu der vereinbarten Bedingung merkte er jedoch kritisch an: „Ein derartiges Verfahren würde einem Kauf jener Standesvorrechte gleichbedeutend sein.“

Auch die Presse nahm herauf keine Rücksicht und kurze Zeit, nachdem die Information über die Standeserhebung veröffentlicht worden war, druckte sie am 20. November 1912 in der Staatsbürger-Zeitung einen giftigen Artikel unter dem Titel Aus unserer Adelsmappe. ${ }^{81}$ Dessen Verfasser konstatierte, dass - wie am 7. November des Monats die Zeitung bekannt gegeben hatte - Wilhelm II. Friedrich Ludwig Gans nobilitiert habe.

79 GStA, I HA Rep. 176 Heroldsamt, Nr. 3230 (Gans).

80 Im Jahre 1910 wurde sein Vermögen auf 16-17 Millionen Mark geschätzt, was ihn auf Platz 96 in der Hierarchie der größten preußischen Steuerzahler erscheinen ließ, Vgl. Drewes, K.: Jüdischer Adel, S. 116.

81 Aus unserer Adelsmappe. In: Staatsbürger-Zeitung (Morgen-Ausgabe), 20. 12. 1912. Hieraus auch das nachfolgende Zitat. Der Artikel findet sich in der Akte Gans im Archiv des Heroldsamts (siehe oben). 
Zugleich jedoch teilte er den Lesern mit, das Schreiben über diese Standeserhebung bereits einige Wochen zuvor gesehen zu haben. Er betonte, der „Jude Friedrich Ludwig Gans“ sei in der Tat eine interessante Person, weil er seine wertvolle Sammlung den staatlichen Museen unter der Bedingung angeboten habe, er selbst werde in den Adelsstand erhoben. Der Verfasser wusste am Ende zu berichten, Gans habe sich vergeblich um ein Baronat bemüht. „Man sieht: Geschäft ist Geschäft. Es handelt sich um eine Leistung und Gegenleistung und von der letzteren lässt sich unter Umständen auch eine Kleinigkeit abhandeln. Der Jude schenkte seine Sammlung und erwarb sich dadurch Verdienste um den Staat. Doch erst jetzt, als er die ersehnte Entlohnung ausgehandelt habe. Vorsicht sei die Mutter der Weisheit. Dies ist der Hintergrund dieser Nobilitierung."

Es ist nicht ausgeschlossen, dass gerade dieses negative Echo der Standeserhebung von Gans dazu führte, dass bis zum Untergang der preußischen Monarchie Ende 1918 keinerlei Nobilitierung von Einzelpersonen jüdischen Glaubens bzw. Herkunft mehr erfolgte. Interesse verdient die Tatsache, dass die reservierte Vorgehensweise Preußens in der Frage einer Erteilung von Adelstitels allgemein (und an Juden sowie jüdische Konvertiten im besonderen) sehr ähnliche Folgen besaß wie die - mit der Existenz eines einfachen Adelswesens verbundene - Inflation von Adelsdiplomen in Österreich in den sechziger bis achtziger Jahren des 19. Jahrhunderts. Ein Teil der liberalen preußischen Gesellschaft nahm daher sowohl gegenüber der Institution des Adelsstandes als auch gegenüber den Titeln eine insgesamt negative Haltung ein. Mit Blick auf die soziale Zusammensetzung des neuen preußischen Adels und die relativ geringen Repräsentanz von Unternehmern in deren Reihen überrascht keineswegs, dass viele von ihnen gerade aus dieser Gesellschaftsschicht kamen. ${ }^{82}$

\section{Zusammenfassung Pruská židovská šlechta}

Postoj jednotlivých evropských států k židům a jejich společenskému postavení byl rozdílný. V habsburské monarchii bylo v letech 1789 až 1918 nobilitováno několik set osob židovské víry (jak v Rakousku, tak později v Uhrách), rovnocenné společenské postavení získali židé až roku 1867. V Prusku se společenské postavení židů vylepšovalo již od vlády Fridricha II. a roku 1812 jim bylo umožněno stát se pruskými občany. Proces židovské emancipace ale završil až zákon o zrovnoprávnění náboženství z července 1869, který byl vyhlášen nejen v Prusku, ale rovnou ve všech státech Severoněmeckého spolku. Ve věci udílení šlechtických titulů nejen osobám židovské víry, ale i původu, bylo ovšem Prusko mnohem zdrženlivější a nobilitace těchto osob zde byly velmi výjimečné.

$82 \mathrm{Zu}$ dieser Frage vgl. Županič, Jan: Inflace titulů? Rakouské nobilitace ve druhé polovině 19. století [Eine Titelinflation? Österreichische Nobilitierungen in der zweiten Hälfte des 19. Jahrhunderts], in: Český časopis historický, 2015, vol. 113, 3/2015, S. 748-781; Drewes, K.: The Invention of Deviance, S. 171-172. 
